\title{
Remote Infrared Imaging of the Space Shuttle During Hypersonic Flight: HYTHIRM Mission Operations and Coordination
}

\author{
Richard J. Schwartz ${ }^{1}$, Andrew C. McCrea ${ }^{2}$ \\ AMA Inc. Hampton, VA 23666 \\ Jennifer R. Gruber ${ }^{3}$, Doyle W. Hensley ${ }^{4}$, \\ NASA Johnson Space Center, Houston TX \\ Harry A. Verstynen ${ }^{5}$, \\ Whirlwind Engineering LLC, Poquoson, VA \\ Timothy D. Oram ${ }^{6}$ \\ NOAA Spaceflight Meteorology Group, Houston TX \\ Karen T. Berger ${ }^{7}$, Scott C. Splinter ${ }^{8}$, Thomas J. Horvath ${ }^{9}$, Robert V. Kerns ${ }^{10}$ \\ NASA Langley Research Center, Hampton VA 23681
}

\begin{abstract}
The Hypersonic Thermodynamic Infrared Measurements (HYTHIRM) project has been responsible for obtaining spatially resolved, scientifically calibrated in-flight thermal imagery of the Space Shuttle Orbiter during reentry. Starting with STS-119 in March of 2009 and continuing through to the majority of final flights of the Space Shuttle, the HYTHIRM team has to date deployed during seven Shuttle missions with a mix of airborne and ground based imaging platforms. Each deployment of the HYTHIRM team has resulted in obtaining imagery suitable for processing and comparison with computational models and wind tunnel data at Mach numbers ranging from over 18 to under Mach 5. This paper will discuss the detailed mission planning and coordination with the NASA Johnson Space Center Mission Control Center that the HYTHIRM team undergoes to prepare for and execute each mission.
\end{abstract}

$\begin{array}{ll}\mathrm{AAC} & =\text { Airborne Asset Coordinator } \\ \mathrm{ADIZ} & =\text { Air Defense Identification Zone } \\ \mathrm{AFB} & =\text { Air Force Base } \\ \mathrm{AFF} & =\text { Automated Flight Following } \\ \text { AFNORTH } & =\text { Air Force North }\end{array}$

Nomenclature

${ }^{1}$ Virtual Diagnostics Lead, AMA Inc, 30 Butler Farm Road, Hampton VA, AIAA Member.

${ }^{2}$ Research Engineer, AMA Inc, 30 Butler Farm Road, Hampton VA, AIAA Member.

${ }^{3}$ Flight Dynamics Officer, Ascent/Descent Flight Dynamics, 2101 NASA Parkway, Mail Code DM46, Houston, TX 77058, AIAA Member

${ }^{4}$ Landing Support Officer, Ascent/Descent Flight Dynamics, 2101 NASA Parkway, Mail Code DM46, Houston, TX 77058

${ }^{5}$ President, Whirlwind Engineering LLC, Poquoson, VA, AIAA Member

${ }^{6}$ Senior Meteorologist, NWS Spaceflight Meteorology Group, 2101 NASA Parkway, Mail Code W58, Houston, TX 77058

${ }^{7}$ BLT Flight Experiment Principal Investigator, Aerothermodynamics Branch, MS 408A, NASA Langley Research Center, Hampton VA 23681, AIAA Senior Member

${ }^{8}$ Aerospace Engineer, Structural Mechanics and Concepts Branch, MS 190, NASA Langley Research Center, Hampton VA 23681, AIAA Member

${ }^{9}$ Aerospace Engineer, Aerothermodynamics Branch, MS 408A, NASA Langley Research Center, Hampton VA 23681, AIAA Associate Fellow

${ }^{10}$ Manager, Space Operations Program Office, MS 494, NASA Langley Research Center, Hampton VA 23681 


\begin{tabular}{|c|c|}
\hline AWIPS & $=$ Advanced Weather Interactive Processing System \\
\hline APL & $=$ Applied Physics Laboratory, Johns Hopkins University \\
\hline BFT & $=$ Blue Force Tracker \\
\hline BLT & $=$ Boundary Layer Transition \\
\hline CCAFS & $=$ Cape Canaveral Air Force Station \\
\hline CEL & $=$ Concept Evaluation Laboratory \\
\hline CFLOS & $=$ Cloud Free Line of Site \\
\hline CFD & $=$ Computational Fluid Dynamics \\
\hline CONUS & $=$ Contiguous United States \\
\hline DOD & $=$ Department of Defense \\
\hline DOPS & $=$ Deorbit Opportunities Processor \\
\hline DOT & $=$ Deorbit Opportunities Table \\
\hline EDW & $=$ Edwards Air Force Base \\
\hline EOM & $=$ End of Mission \\
\hline FAA & $=$ Federal Aviation Administration \\
\hline FDO & $=$ Flight Dynamics Officer \\
\hline FE & $=$ Flight Experiment \\
\hline FOV & $=$ Field of View \\
\hline GAC & $=$ Ground Asset Coordinator \\
\hline GMT & $=$ Greenwich Mean Time \\
\hline HAC & $=$ Heading Alignment Cone \\
\hline $\mathrm{HF}$ & $=$ High Frequency \\
\hline HFGCS & $=$ High Frequency Global Communication System \\
\hline HST & $=$ Hubble Space Telescope \\
\hline HYTHIRM & $=$ Hypersonic Thermodynamic Infrared Measurements \\
\hline ISCCP & = International Satellite Cloud Climatology Project \\
\hline ISS & $=$ International Space Station \\
\hline JSC & $=$ Johnson Space Center \\
\hline KSC & $=$ Kennedy Space Center \\
\hline LSO & $=$ Landing Safety Officer \\
\hline MARS & $=$ Mobile Aerospace Reconnaissance System \\
\hline MCC & $=$ Mission Control Center \\
\hline MEP & $=$ Mission Execution Plan \\
\hline MEPC & $=$ Mission Execution Plan Coordinator \\
\hline MOD & $=$ Mission Operations Division \\
\hline MODTRAN & $=$ MODerate resolution atmospheric TRANsmission program \\
\hline MPT & $=$ Mission Planning Team \\
\hline NAS & $=$ Naval Air Station \\
\hline NESC & $=$ NASA Engineering and Safety Center \\
\hline NOAA & $=$ National Oceanic and Atmospheric Administration \\
\hline NOR & $=$ Northrop landing Strip, White Sands, New Mexico \\
\hline NM & $=$ Nautical Mile \\
\hline $\mathrm{OA}$ & $=$ Orbital Adjust \\
\hline OMS & $=$ Orbital Maneuvering System \\
\hline OOP & $=$ Out-Of-Plane \\
\hline PCA & $=$ Point of Closest Approach \\
\hline $\mathrm{SOC}$ & $=$ Support Operations Center \\
\hline SMG & $=$ Spaceflight Meteorology Group \\
\hline SSPO & $=$ Space Shuttle Program Office \\
\hline STS & $=$ Space Transportation System \\
\hline TPS & $=$ Thermal Protection System \\
\hline TSP & $=$ Test Support Plan/Position \\
\hline USFS & $=$ United States Forest Service \\
\hline ViDI & $=$ Virtual Diagnostics Interface \\
\hline
\end{tabular}




\section{Introduction}

$\mathrm{T}$ he Hypersonic Thermodynamic Infrared Measurement (HYTHIRM) team has successfully conducted seven missions to obtain spatially resolved, calibrated thermal infrared imagery of the Space Shuttle Orbiter as it reenters the Earth's atmosphere over a period of more than two years. Starting with STS-119 in March of 2009 and for six additional missions data was acquired by a specially modified US Navy P-3 aircraft referred to as CAST GLANCE. Additionally, the Clay Observatory's Mobile Aerospace Reconnaissance System (MARS) ground based units deployed four times starting with STS-119, and successfully captured data on two Orbiter reentries. Infrared imaging of the Orbiters has captured resolved imagery data from over Mach 18 to under Mach 5, although not contiguously.

Each mission posed unique challenges to the HYTHIRM team. The desired Mach number observations, Orbiter attitude during reentry and weather played key roles in determining how an observation was made. Additional factors faced by the team included the mobility of the imaging platforms to cover landing wave-off contingencies, flight through foreign airspace, aircraft basing constraints, crew rest issues and the continuous possibility of last minute changes in the Space Shuttle mission itself. A key challenge became the ability to point a camera with an exceedingly narrow field of view at the correct location in the sky at the precise moment in time to capture a one hundred twenty three foot long vehicle traveling at over ten thousand miles per hour. While doing so, the camera had to capture scientific quality calibrated imagery. This required thorough preparation, powerful and quick-toimplement simulation tools, and a dynamic government, contractor, DOD and university team with varied and complementary skill mixes.

During a HYTHIRM mission, the team was comprised of three main elements. First, there were the imaging asset operators. These individuals were responsible for placing the imaging platform (ground or airborne) at the correct position and then acquiring imagery of such caliber as to be converted into scientific data with well understood uncertainty bounds. The second group was responsible for obtaining thermal, spatial and radiometric calibration data of the thermal imaging systems that were fielded. The third group was based at the NASA Johnson Space Center (JSC) Mission Control Center (MCC). This group was made up of three sub-groups - (i.) Project Management, (ii.) the Science Team, and (iii.) the Mission Planning Team (MPT). Individuals from these groups worked closely with members of the JSC Mission Operations Directorate (MOD), consisting of the Space Shuttle mission controllers, as well as the National Oceanic and Atmospheric Administration (NOAA) Spaceflight Meteorology Group (SMG), also based at MCC. This paper will concentrate on how the HYTHIRM Team members at JSC integrated with and operated from MCC to provide technical guidance and management decisions for maximizing the opportunities to successfully acquire high fidelity infrared imagery data.

\section{A. Scientific Rationale}

Comprehension of the fundamental physics of hypersonic boundary layer transition has been a critical yet underdeveloped realm of aerothermodynamics. Predictions on when and how a boundary layer will transition from laminar to turbulent flow and potentially back to a laminar state directly affect the ability to predict vehicle drag, thermal loads, and the mass of the vehicle. The result is a perpetual necessity to over-engineer flight hardware and/or place operational restrictions on vehicles designed to operate in this extreme environment. Obtaining spatially resolved temperature distributions across the windward surface of hypersonic vehicles in flight was a critical step in advancing the state of the art of understanding hypersonic boundary layer transition, which will lead to the optimization of future designs and operational limitations.

\section{B. Historical Development}

A limited series of infrared imaging experiments have been conducted in the past ${ }^{1-7}$, dating back to the third Space Shuttle flight in the early 1980's that have attempted to acquire infrared imagery of the Orbiter during descent. More recently, airborne assets intended to image the Orbiter on ascent were utilized in an "adhoc" fashion to obtain infrared imagery during reentry. The early results were mixed (Figure 1), but the lessons learned were invaluable to gaining insight into how to

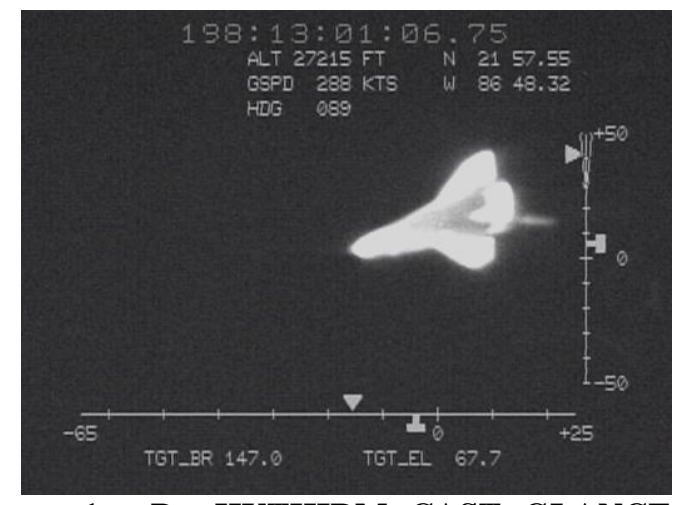

Figure 1. Pre-HYTHIRM CAST GLANCE IR image from STS-121. Most of the Orbiter is saturated, and resolution is lower than used for later HYTHIRM missions, but this image proved the concept was possible. 
proceed with acquiring engineering quality infrared imagery of the Space Shuttle during descent. Using the lessons learned from those previous efforts, the HYTHIRM team developed a process for continual improvement and expansion of mission capabilities. This has allowed the team to posture itself to work around the inevitable challenges and take advantage of whatever opportunities presented themselves in order to successfully complete the mission.

The HYTHIRM project began in 2008. It was sponsored by the NASA Engineering and Safety Center (NESC) with the mandate to determine the feasibility of acquiring spatially resolved, thermally calibrated imagery of the Space Shuttle Orbiter during reentry. The outcome of this study was positive ${ }^{8-10}$, resulting in the Space Shuttle Program Office (SSPO) providing resources to attempt an airborne data collection mission starting with STS-119 in March of 2009. Following a successful data collect on STS-119, the HYTHIRM team continued to receive SSPO support for STS-125, STS-128, STS-131, STS-132, STS-133 and STS-134. Each mission has returned high quality spatially resolved, scientifically calibrated in-flight imagery data.

\section{Space Shuttle Boundary Layer Transition (BLT)Flight Experiment (FE)}

Independent of the HYTHIRM project, a flight test experiment to determine the behavior of the hypersonic boundary layer was undertaken in which a special TPS (Thermal Protection System) tile (Figure 2) with a carefully shaped protuberance was located on the underside of the port wing of the Orbiter ${ }^{11,12}$. This modification (along with additional thermocouples located in strategic areas) was initially made to the Orbiter Discovery (OV-103), and has also been added to Endeavour (OV-105) for its final flight, STS-134. Over the life of this experiment boundary layer trips of three increasing sizes have been flown. HYTHIRM imaging has occurred for each of the BLT FE flights. The high temperature flow created by the turbulence aft of the boundary layer trips has been clearly measured by the HYTHIRM data.

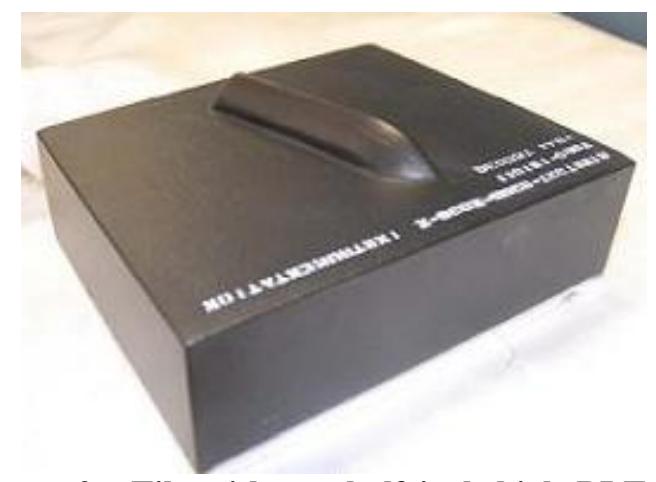

Figure 2. Tile with one-half inch high BLT FE protrusion to be mounted on underside of Orbiter wing. This was the largest protrusion to be flown.

\section{Processed Data Products}

While beyond the scope of this paper, and well documented in references ${ }^{13,14}$, it bares mentioning that the imagery data acquired during the HYTHIRM missions has proven to be of very high quality (Figure 3). Agreement between flight data temperature measurements and CFD has been shown to be within $2 \%$ under conditions where predictions are known to be well behaved.
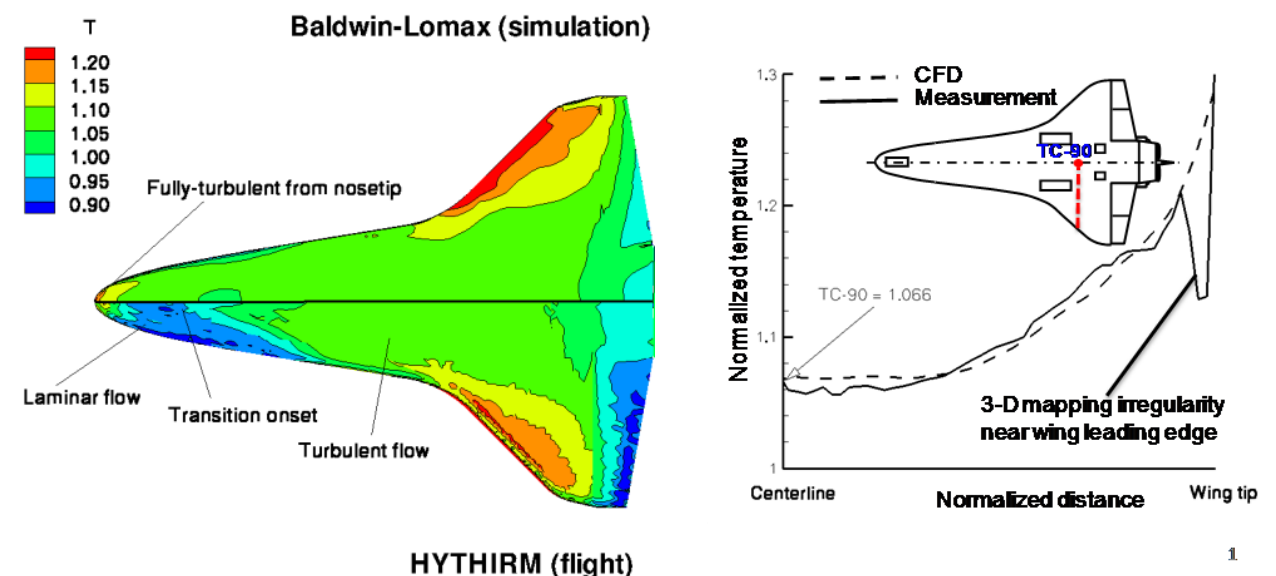

HYTHIRM (flight)

Figure 3. Comparison of HYTHIRM flight data from STS-119 with computational predictions. The upper portion of the Orbiter image on the left is a solution from a fully turbulent prediction; the lower half is flight data which includes laminar flow at the nose with transition to fully turbulent flow by one-third the length of the vehicle. The plot on the right compares temperature along the indicated line from centerline to wing leading edge. 


\section{Early HYTHIRM Preparations - Simulation and Training}

Simulation and training activities were critical for the HYTHIRM team in preparation for the first mission. The activities were designed to maximize success by giving the team the ability to perform missions with personnel trained in effective communications and information flow as well as allowing the team to determine how to operate within the realm of MCC with no significant impact to Space Shuttle operations. Additional critical aspects included the development of a timely and responsive weather reporting system with SMG and methods of effective communications/operations with the imaging asset operators.

\section{A. Observing Spaceflight Operations}

Prior to the start of the official training and simulation phase of the program, a single team member observed nominal Space Shuttle operations and reentry procedures for STS-124 in May of 2008. This was followed in November of 2008 by a small number of team members (referred to as the Training and Simulation group) who observed/participated in the STS-126 mission. This allowed the HYTHIRM team to produce operational mission timelines and solidify interfaces with critical contacts such as the Flight Dynamics Officer (FDO), Landing Support Officer (LSO), and SMG. The first draft of the Mission Execution Plan (MEP), discussed below, also emerged from this experience. Coming out of STS-126 the Training and Simulation group was well positioned to initiate planning for the extended training and simulation activities that would include the rest of the HYTHIRM team. The planning phase concluded in December of 2008.

\section{B. Desktop Training}

The training phase of the program was conducted using a desktop training format, allowing each member to work at their own pace on a PC workstation. The Mission Planning Team (MPT) developed familiarity with specialized Virtual Diagnostics Interface (ViDI) EntrySim3D software. This software allowed the team to visualize the trajectories provided by the FDOs and simulate camera views from the aircraft in an interactive threedimensional virtual environment (discussed in detail below). Asset operator training was completed at their respective home bases and included transferring a series of reentry trajectories to test compatibility with their computer systems and for use in developing flight plans. Desktop training ran from mid December 2008 until mid January 2009. This allowed the team to identify hardware, software, and communication needs prior to the JSC MCC Simulation Phase.

\section{JSC MCC Simulation Exercise}

The JSC Simulation Exercise was conducted in January of 2009 in the MCC at JSC, which is where Project Management, the Science Team and the MPT would conduct future HYTHIRM missions. The asset operators participated from their home bases via telecon. The simulation activities covered events that would occur at the End of Mission (EOM) day, picking up several hours before reentry. The Science Team determined the optimal observation points based on Mach number. In response the asset imaging operators were able to create detailed Test Support Plans (TSP).

A total of three re-entries were simulated. Weather conditions were supplied by SMG, and Orbiter flight parameters were played back on the FDO computer console displays from actual shuttle reentries. These included a nominal re-entry to KSC (based on STS-124), one orbit wave off to KSC (based on STS-123) and a re-entry to EDW (based on STS-126). The simulation allowed the team to test communication and coordination planning prior to the STS-119 mission. Simulated trajectories were provided by the FDO at the appropriate time for plotting with the ViDI EntrySim3D toolset on both a primary and backup laptop computer simultaneously. The JSC High Speed Entry Processor (the display system used by the FDOs) was used as a backup for visualizing the trajectories. Each person on the HYTHIRM team had an assigned backup, and both primary and backup personnel participated in the simulation.

\section{Simulation and Training Lessons Learned}

The simulation and training activities were essential for pre-mission preparations, and a list of the most important lessons learned is given below.

1) "Blackout" zones were added to target Mach numbers to allow assets to position themselves to find suitable weather while clearly marking areas to avoid, such as near roll-reversals. 
2) The ViDI tool was updated to include distances in nautical miles, changes from subsequent trajectories to calculate updated latitudes/longitudes, international airspace boundaries and standoff distances for foreign countries.

3) GMT would be used to coordinate all groups and events over the several time zones of operation.

4) The best communication methods with CAST GLANCE were via High Frequency (HF) radio and iridium satellite phone.

5) Because nominal SMG Shuttle weather reports are specific to landing sites, HYTHIRM unique resources were provided by SMG on a special HYTHIRM weather website.

\section{HYTHIRM Mission Operations - Tools and Preparation}

HYTHIRM mission operations began months prior to the reentry date and encompassed a wide array of activities to prepare for the scientific, logistic, hardware, software and human aspects of each mission. The procedures evolved over the three years of operation, and while aspects may be repetitive, they could not be considered routine. This section of the report will describe the elements that go into conducting the operations of a HYTHIRM mission.

\section{A. Mission Execution Plan}

Obtaining HYTHIRM imagery has been a dynamic logistical effort that required the gathering, analysis, and dissemination of time-critical information. In order to assure that the proper information was received and distributed at the proper time, the Mission Execution Plan, or MEP was created. In its earliest form it was a checklist. It evolved into a comprehensive document encompassing a wide range of reference information. Originally it was considered to be mission neutral, but starting with STS-132 the MEP was tailored to specific events and requirements for each mission.

In addition to a detailed checklist that began two weeks prior to the launch of the Shuttle, the MEP contained information such as the requirements for weather information from SMG, trajectory file naming and formatting conventions, plans for airspace coordination, foreign deployment, asset communications and the conducting of the dress rehearsals. The MEP was maintained by the Mission Execution Plan Coordinator (MEPC), an individual responsible for the upkeep of the document as well as ensuring that MEP procedures are being followed as the mission progresses.

\section{B. Determining Observation Points to Satisfy the Science Objective}

The general consensus of the aeroheating technical community is that accurate measurement of surface temperature associated with a high Mach number, fully developed, turbulent flow is of significant benefit to the design and engineering teams. High Mach number turbulent data is followed closely by laminar surface temperature data under conditions where flow chemistry is present generally near peak heating, or approximately Mach 21 for the Shuttle. The actual imaging observation location is determined by a careful trade of maximizing scientific return against asset instrumentation, logistical, and/or weather constraints that present themselves during the course of the mission leading up to the day of reentry. The goal was to observe at locations that corresponded to Mach numbers where BLT FE was expected to produce elevated heating (flow turbulence) downstream of a strategically placed protuberance on the Orbiter's wing. On flights where the experiment was not flown, observation locations were evaluated against Mach numbers where tile damage, if present, was expected to produce flow transition to turbulence. In the absence of TPS damage, consideration was given

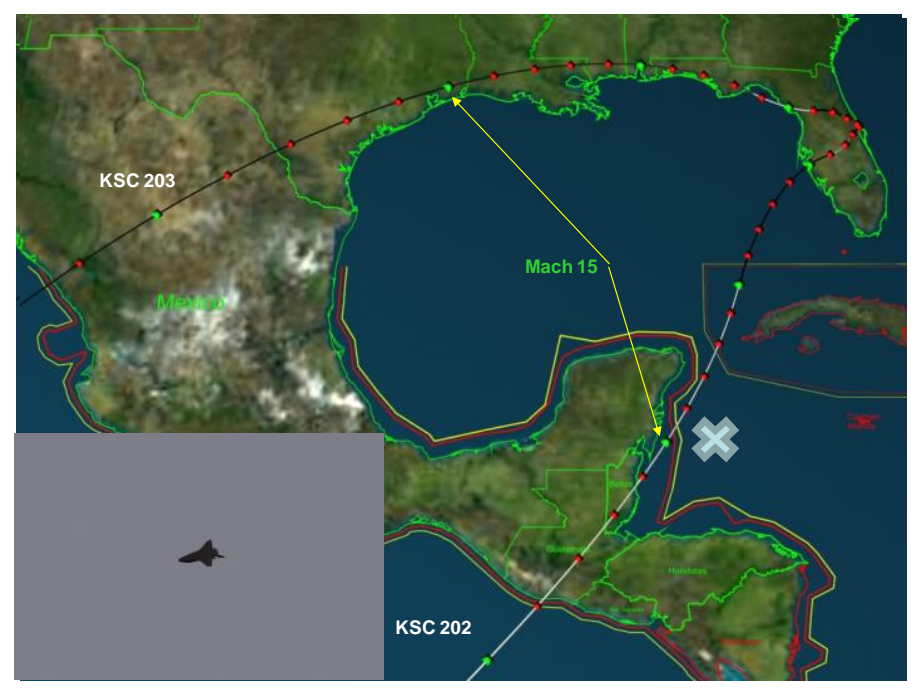

Figure 4. Graphical output from the ViDI Entrysim3D toolset includes trajectories with integer Mach numbers indicated by dots. Global display includes political boarders and foreign airspace boundaries. The inset image is a simulated camera view of the Orbiter as it passes the airborne imaging asset indicated by the large " $X$ " in the image. 
towards obtaining imagery at conditions where laminar flow existed at high Mach location.

Graphical-based simulation tools (ViDI) were used to re-assess and fine-tune the observation location near the day of reentry. These simulations showed the anticipated Orbiter ground track and where the Shuttle was expected to execute roll bank (energy management) maneuvers. The ground track and orientation of the Shuttle potentially constrained the ability of the asset to obtain the desired science (Figure 4). If the desired imaging Mach number required transit or loitering over foreign airspace then diplomatic clearances would be required. If a roll reversal was projected to occur near the desired science, then the observation location needed to be moved to insure the desired view was maintained. High altitude cirrus clouds and the position of the sun also influenced the ability of the asset to collect the imagery by obscuring the desired view or damaging the focal plane array with intense sunlight. After all constraints were assessed simulated camera views were developed which model the relative positions of the imaging assets and the Orbiter. If required a series of simulations are quickly produced which provided a trade study to analyze the constraints on the viewing angle, spatial resolution and time on target.

\section{Space Shuttle Reentry Trajectories}

The Space Shuttle reentry trajectory is the most critical piece of information in planning and executing a HYTHIRM mission. Each trajectory contained information that drove the science decision of where to image the Orbiter. These constraints included the physical location of the asset, political borders, air traffic control, flight hours, ground travel and mobile telescope basing, and expected weather patterns. Due to the operational flexibility of the Space Shuttle, the reentry trajectories can change in a moment, and can vary significantly. Given the importance of the trajectories to HYTHIRM, it became essential to understand how the trajectories were derived and how they changed from the days to just minutes before the vehicle performed it's de-orbit burn to initiate reentry. Given the importance of the trajectories to the HYTHIRM project, this section will provide insight into the elements that define and determine the evolution of the trajectories.

\section{Shuttle Reentry Description}

All of the Shuttle missions supported by HYTHIRM rendezvoused with the International Space Station (ISS) at 51.6-degree inclination except for STS-125, which rendezvoused with the Hubble Space Telescope (HST) at 28.5-degree inclination. The major factors that affect deorbit and reentry trajectories will be discussed in terms of ISS-rendezvous missions, but similar concerns are applicable to non-ISS missions.

To initiate reentry, a deorbit burn occurs that uses the two Orbital Maneuvering System (OMS) engines to place the perigee of the vehicle's orbit within the atmosphere. Once this propulsive maneuver is complete, the vehicle is in essence unpowered, relying on maneuvering thrusters to provide attitude control prior to the aerodynamic control surfaces becoming effective. The on-board computers guide the vehicle along a path that is computed in real time based on vehicle position and velocity. This path or trajectory is defined by its crossrange to the landing field.

In a simplified definition the crossrange is the distance the vehicle must travel left or right of its current unaltered path to get to the landing site. This distance is set by the location of the Orbiter at the time of the deorbit burn, and can range from several hundred miles right to several hundred miles left of a direct path (center line) to the landing site.

During reentry, the vehicle must carefully manage its energy such that it will slow from the 17,500 miles per hour orbital velocity to a touchdown at the end of a

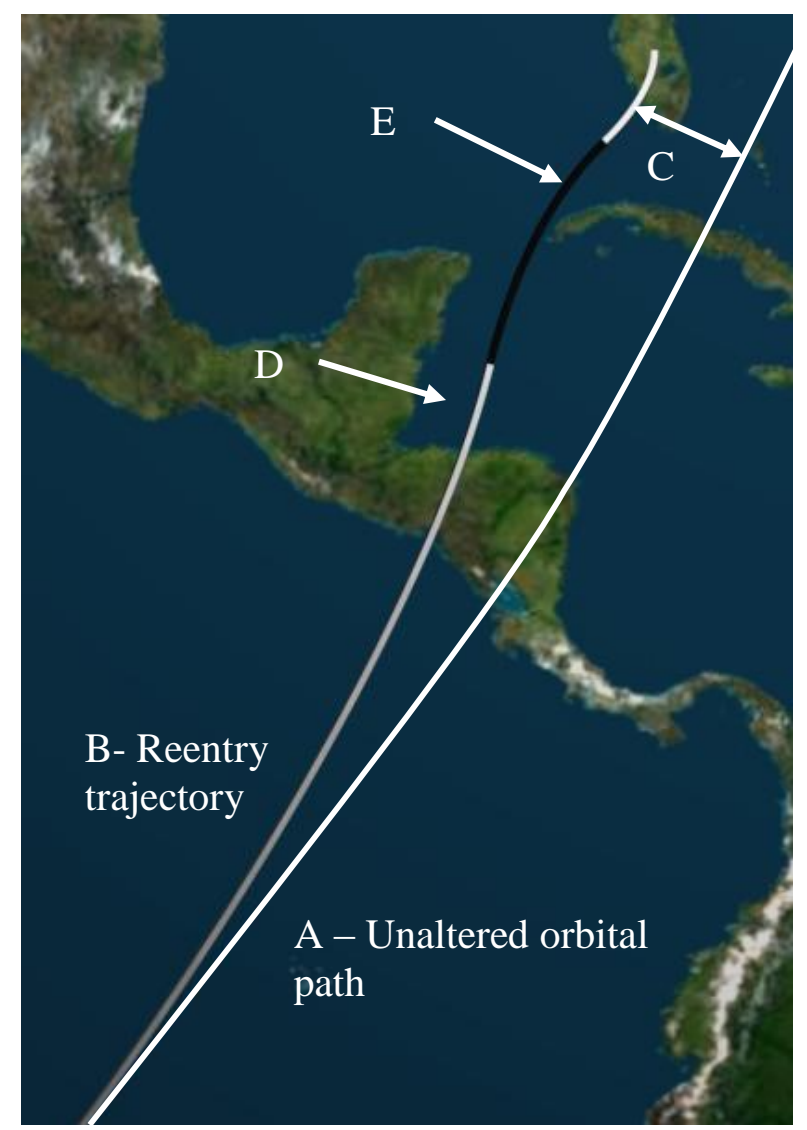

Figure 5. Space Shuttle Orbiter Reentry Trajectory description. Line A represents the orbital path if there would be no deorbit burn. Line $\mathrm{B}$ is the entry trajectory to $\mathrm{KSC}$, and Line $\mathrm{C}$ represents the crossrange. Points $D$ and $E$ depict the roll reversals used for energy management and crossrange control. 
runway at about 200 miles per hour. The braking mechanism is primarily aerodynamic drag. To control this energy, while preserving crossrange capability, the vehicle will fly a series of banking maneuvers, with bank angle determined by the amount of energy that must be lost. After flying banked for a period of time, the vehicle will deviate from the center line pointing to the runway. To control crossrange, on-board guidance limits the amount of deviation from center line. Once the vehicle reaches this limit, it turns from banking in one direction to banking in the opposite direction. This is called a "roll-reversal". If the Orbiter has a large crossrange at deorbit, it will bank toward the landing site for a longer period, and thus cross the center line and reach the limit for the first roll-reversal later, resulting in fewer total roll-reversals (as few as one). Conversely, if the crossrange is smaller, the first rollreversal will be earlier, and there will be more total roll-reversals (as many as four). (Figure 5). To fine adjust the energy of the Orbiter just prior to landing the vehicle will fly a circular path referred to as the Heading Alignment Cone, or $\mathrm{HAC}$, where the exact radius of the $\mathrm{HAC}$ can be adjusted to properly manage the remaining energy.

\section{2. $\quad$ Factors Affecting Reentry Trajectories}

The Orbiter's reentry trajectory is dependent on the earth-relative position of the Orbiter at the time of deorbit. Factors that affect this position include the launch date and duration of the mission, the crew timeline, and the time of undocking. The launch date is dependent on numerous criteria, including several rendezvous requirements, such as orbit planar and phasing constraints, and thermal constraints due to solar beta angle.

The next constraint to consider is mission duration. Normally set prior to launch, it is not unusual for the duration to be extended once the vehicle is on-orbit, based on the need to complete tasks or conduct troubleshooting. The mission duration sets the time for the nominal deorbit burn, and in turn, sets up the conditions for the reentry. Weather permitting, reentry is usually two days after the Orbiter undocks from the ISS.

Another factor that will affect the Orbiter's entry trajectory is the choice between a descending and ascending node opportunity (Figure 6). During an ascending entry the Orbiter will fly from the south on a northerly path to the landing site. This will carry the vehicle over some portion of Mexico or Central America and the Gulf of Mexico on its way to a landing in Florida. For a descending approach, the Orbiter will be flying toward the descending node (from the north in a southerly path) for the majority of the entry. A descending node reentry will bring the vehicle over the continental United States north of California and sweeping down toward Florida. Descending opportunities occur approximately every eight hours after ascending opportunities.

It is rare for the Orbiter to fly a descending node reentry. Descending opportunities require more propellant due to the atmospheric density gradient relating to the equatorial bulge. In the summer months noctilucent clouds (high altitude clouds with ice particles) that occur over higher latitudes are also a concern. Occasionally, the Shuttle Program will choose to deorbit on descending opportunities. One reason to choose a descending deorbit would be to better align the Shuttle crew timeline with that of the ISS crew, to eliminate the need for either crew to aggressively sleep shift (as with STS-131). Another reason to choose descending opportunities would be to provide a daylight landing. During the STS-120 mission the Shuttle Program switched to descending deorbit mid-flight after the mission duration was extended. Providing the Shuttle's Commander with a daylight landing was preferable in this case due to human factors issues (de-conditioning) resulting from the longer mission.
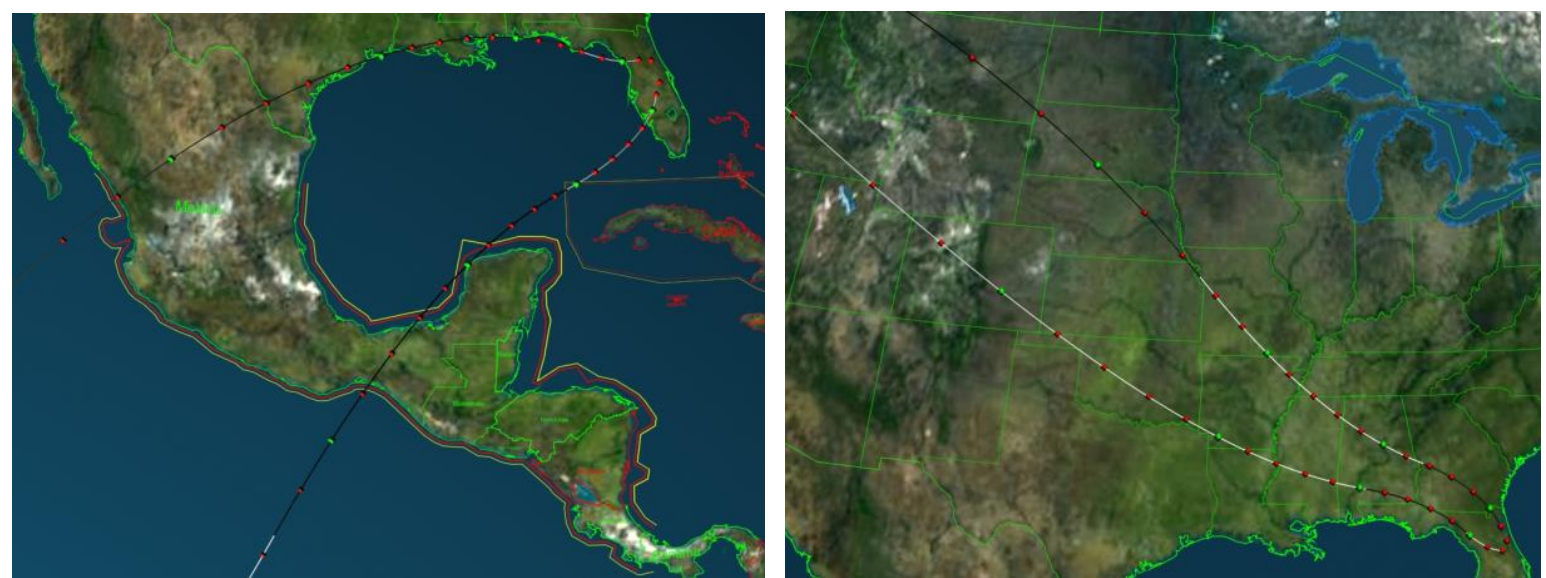

Figure 6. Left is a typical set of ascending node trajectories, right are examples of descending node trajectories. STS-131 was the only descending node reentry observed by HYTHIRM, which utilized mobile ground based telescopes. HYTHIRM operational considerations for ascending and descending nodes are considerably different. 


\section{Determining Reentry Trajectories}

To determine which orbits have viable deorbit opportunities to a specific landing site, a processor called Deorbit Opportunities Processor (DOPS) is run against the Orbiter's post-undock trajectory. DOPS calculates the crossrange between an orbit and landing site at the closest point of approach and creates a table listing landing sites, times, and crossranges for those opportunities that meet crossrange constraints.

Crossrange limits are unique for each mission and are dependent on orbital altitude, mass properties, and atmospheric conditions. The limits are generally on the order of 800 nautical miles (NM) either side of the landing site. Table 1 shows an example of a Deorbit Opportunities Table (DOT) for the three main Shuttle landing sites, Kennedy Space Center (KSC), Northrop/White Sands (NOR), and Edwards Air Force Base (EDW). The large crossrange capability of the Shuttle results in a wide range of potential entry trajectories into a given landing site, and additional planning challenges for trajectory-dependent operations such as HYTHIRM.

Beyond the limits imposed by orbital mechanics, the choices of acceptable crossranges are dictated by a number of operational constraints. The highest priority constraint is to have two opportunities to land at each of the three main landing sites on $\mathrm{EOM}, \mathrm{EOM}+1$ day and $\mathrm{EOM}+2$ days, enabling operational flexibility in case bad weather or spacecraft malfunctions force a wave-off for one orbit (90 minutes) or a one day delay. Another constraint, imposed on trajectories into EDW and NOR is to avoid crossranges whose entry trajectories overfly areas with certain population densities, resulting in an unacceptable risk to the public in the event of a breakup.

In order to provide a set of deorbit opportunities that meet desired constraints, an orbit adjust (OA) burn may be performed after undock to adjust subsequent deorbit opportunity crossranges. Often, orbit adjust planning is discussed pre-mission, but is not rigorously considered until several days into a mission when the operations team has a better understanding of the true flight plan, accounting for any anomalies the mission experiences. Therefore, potential orbit adjusts are often not modeled pre-flight, and the HYTHIRM team must wait until post-dock to have a realistic assessment of the possible deorbit opportunities. Once the orbit adjust is planned sometime between docking and the official FDO delivery of the predicted entry trajectories on EOM-2 days, a preliminary DOT is published (Table 1). JSC flight design personnel use this planning DOT to provide the HYTHIRM team initial approximate entry trajectories as quickly as possible.

Table 1. Example of deorbit opportunities table (DOT). ORB refers to the number of orbits flow, TIG is time of ignition given in Mission elapsed time (MET), landing time and lighting conditions for landing. The crossranges for the three landing sites, EDW, NOR and KSC are listed in nautical miles, with "A" referring to an ascending node and " $R$ " or " $L$ " indicating the vehicle will approach the landing site from either the left or the right.

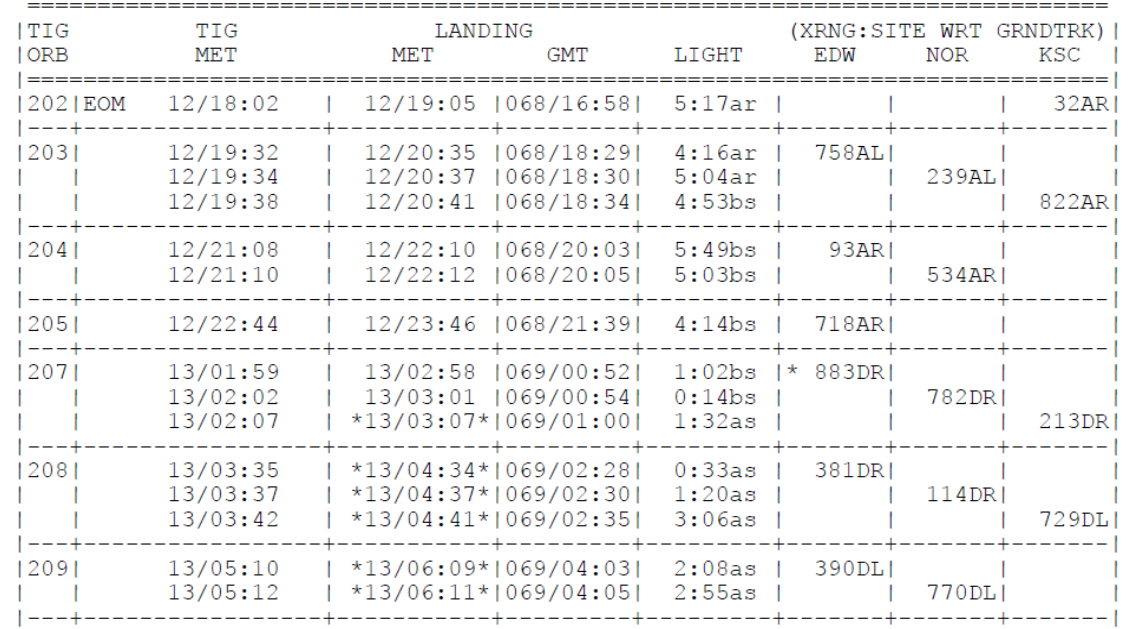

\section{Crossrange Constraints Relating to the BLT FE}

An important aspect of the BLT FE is the measurement of temperatures near the surface of the vehicle during reentry. This is accomplished through the use of thermocouples careful mounted within the tiles of the TPS. Operational experience has shown that during periods of flight when the vehicle undergoes a roll reversal, the thermocouples can act in unexpected ways. This phenomenon is not currently understood and results in rapid and sustained changes to the temperature measurements. Thus, to minimize these periods of data dropout, crossrange constraints that avoid roll reversals prior to boundary layer transition at the protuberance are preferred. If that is not 
possible then it is desirable to avoid roll reversals within plus-or-minus one Mach number of the predicted transition. Since manually overriding the flight computer is not an option to alter the roll reversal timing, the only safe way to ensure BLT FE roll reversal constraints are met is to provide deorbit opportunities with certain crossranges. This is done by targeting larger crossranges to avoid roll reversal prior to BLT, or to cut out specific crossranges to avoid reversals around predicted transition. It is important to note that meeting the BLT FE crossrange constraints are a low priority, and would be accommodated only if such constraints also fulfilled the higher priority considerations.

The HYTHIRM team received alternative sets of trajectories prior to launch of STS-133 and STS134 that take into consideration the BLT FE flight rule (Figure 7). Due to numerous other operational constraints during the mission, a decision on whether to utilize the alternative or the nominal trajectories is made in the days prior to reentry, requiring the HYTHIRM team to maintain flexibility in adjusting to the mission.

STS-133 was extended two days, with two separate decisions (one extension day at a time) after docking. An orbit adjust burn was performed the day before entry to provide two opportunities to KSC on EOM. Due to orbital mechanics and propellant limitations, the orbit adjust to meet the high priority constraint of two KSC opportunities

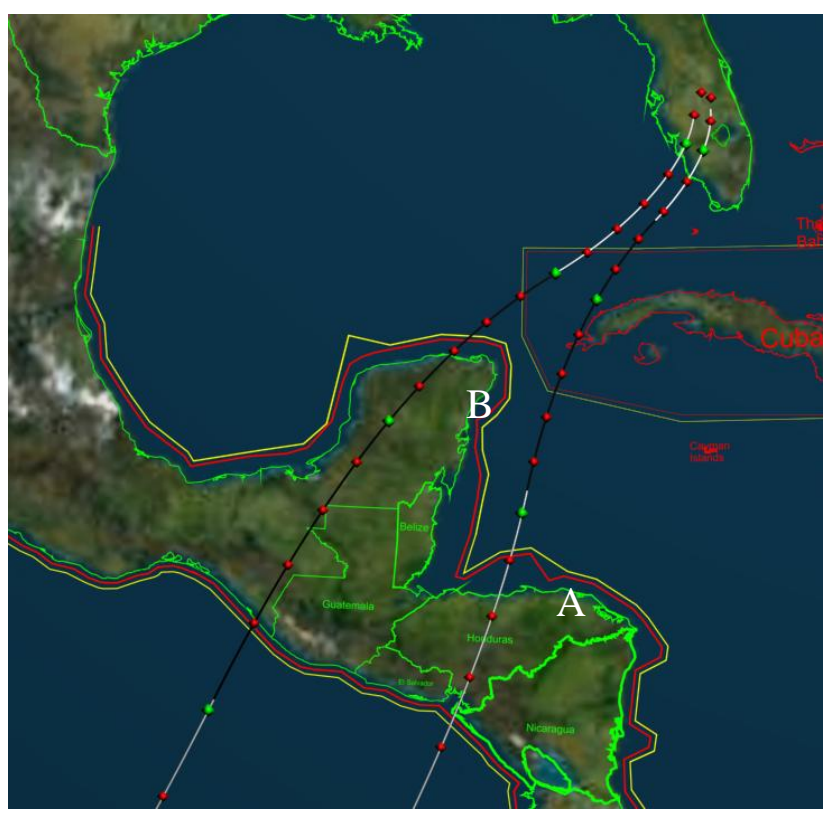

Figure 7. Example of nominal (Line A) and alternative (Line B) trajectories for BLT DTO consideration for STS-134. The change in HYTHIRM observation point may be hundreds of nautical miles.

on EOM could not simultaneously meet the BLT FE constraint for a larger crossrange on the first of the two opportunities. The Orbiter reentered on the first opportunity, resulting in a small crossrange. This required the Orbiter to experience a roll-reversal prior to the boundary layer transition caused by the BLT FE. Even though the roll-reversal occurred at more than a full Mach number prior to the transition, the thermocouples were perturbed due to this maneuver.

\section{Trajectory Visualization and Imaging Camera Simulation}

As mentioned above, all aspects of HYTHIRM mission planning begin with the trajectory information provided by the FDOs. Understanding and communicating key parameters of each of the multitude of trajectories provided by the FDOs, before and during each mission, is essential for the project.

\section{Concept Evaluation Laboratory FUSION Capability}

At the start of the HYTHIRM project a trajectory visualization toolset derived from ViDI technology was developed, using technology originally devised at NASA Langley for simulating wind tunnel and flight test instrumentation. However, due to the tight time constraints and the need for validation of the simulation, a second source for visualization was employed. The Concept Evaluation Laboratory (CEL) at JSC had a software package called FUSION that had similar capabilities to ViDI, but was more fully developed and validated from previous spaceflight applications. For STS-119 and STS-125 the HYTHIRM team was able to occupy the CEL and request the FUSION operators to plot the trajectories and simulate the view from the imaging asset (Figure 8). In addition, identical input conditions were processed ViDI. After comparing output and verifying that ViDI was in agreement with FUSION the validated ViDI toolset became the standard tool from STS-128 onward. There were two primary reasons for this. First, the ViDI tool could be optimized to meet the requirements of the HYTHIRM project by HYTHIRM personnel, and secondly it could be run on a PC workstation class laptop computer, making this capability mobile. It was used in MCC and in the field, especially with the ground based imaging systems. The CEL maintained situational awareness for the consecutive HYTHIRM missions as a backup capability. 

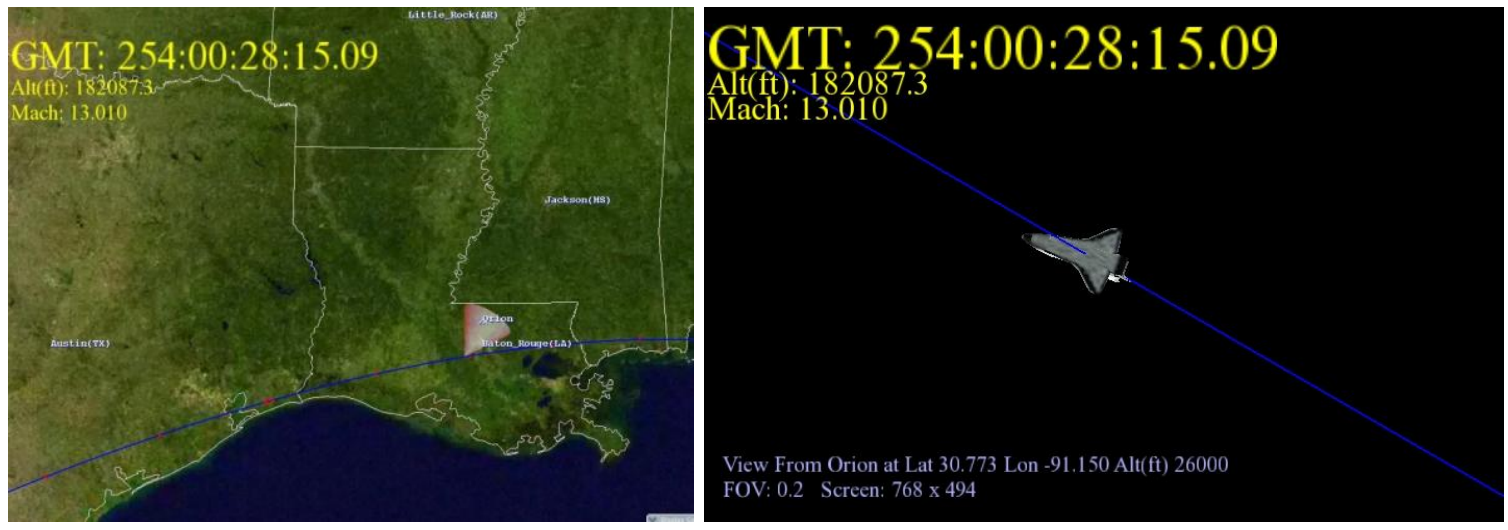

Figure 8. Sample output from FUSION showing the Orbiter ground track on the left, and a simulated view of an airborne asset at a given standoff distance.

\section{Virtual Diagnostics Interface EntrySim3D}

The first incarnations of the ViDI EntrySim3D program were created in the formative period of HYTHIRM using a combination of an industry standard, commercial-off-the-shelf, three-dimensional computer modeling, visualization and animation program and customized applications derived from previous NASA work ${ }^{15}$. Entrysim3D was used extensively for plotting trajectories in the three-dimensional, global virtual model. However, it took longer to incorporate the proper orientation of the Orbiter (roll, pitch and yaw) at each time step along the trajectory. As mentioned above, the FUSION tool was used while this capability was being added and validated to the software.

The EntrySim3D program was tailored to read in the trajectory files in a number of different formats commonly encountered by the HYTHIRM team. When the Shuttle trajectories were read in key identifying information either in the filename or in a data header were parsed out and stored such that the user is typically not required to manually enter any data. This eliminated user error and streamlined the process. The trajectory data was then used to create a three-dimensional path within a three-dimensional virtual model of the Earth using the geodetic latitude, longitude and altitude provided (Figure 9). For HYTHIRM purposes a simple ellipsoid model of the Earth with the average polar and equatorial radii defining the spheroid was used. The Earth model also included political boundaries and country names, as well as the ADIZ boundaries for entering foreign airspace. Additionally, the borders of countries were set to green if clearance has been obtained to enter their airspace, yellow if clearance was pending, or red if the aircraft would not be

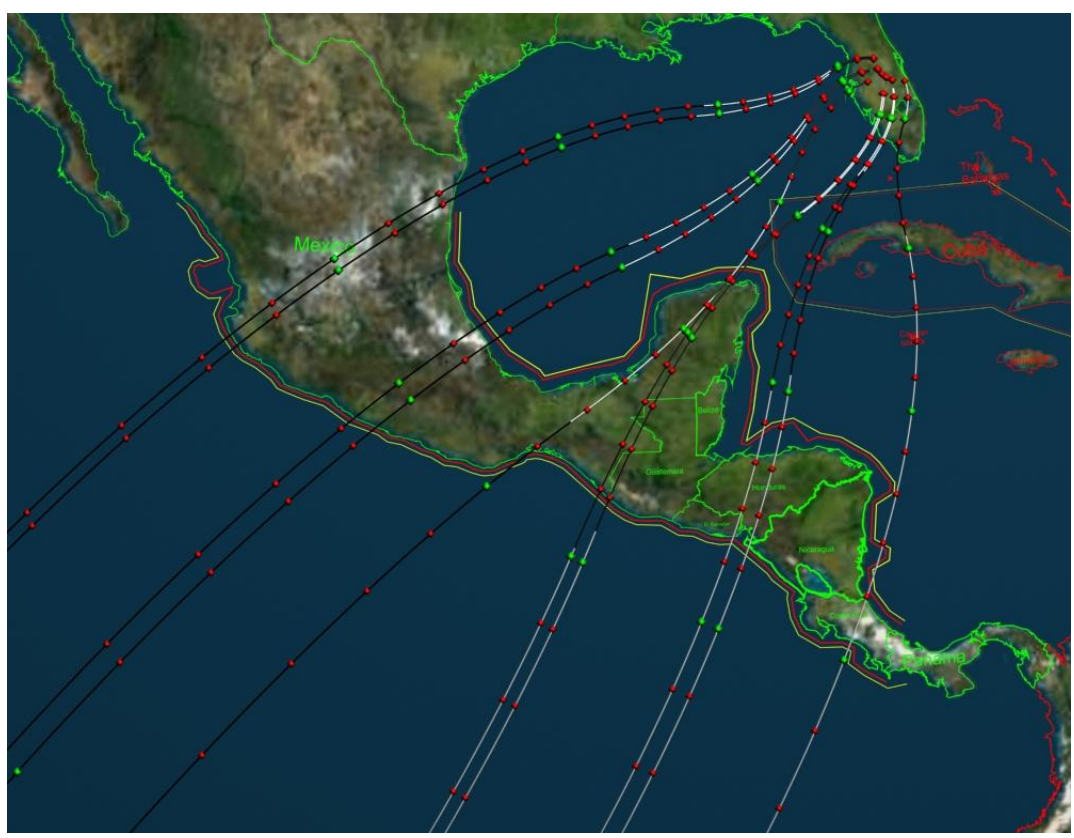

Figure 9. EntrySim3D plotting of all possible trajectories into KSC for a given launch date for STS-134. The black portion of the lines represent the Orbiter's right wing down in a bank, the white portion is a left wing down bank; the color change is the location of the roll reversals. The red spheres are integer Mach numbers, the green spheres are Mach numbers divisible by 5 . Country boarders with diplomatic permission for over-flight of the HYTHIRM aircraft are in green; those without permission are in red. The red outline of the coast is the boundary between international airspace and foreign airspace, and the parallel yellow line is a "safety" standoff reference. 
allowed to fly within that airspace.

When displaying the trajectories the program placed a sphere at each integer Mach number value; green at values divisible by five, red at all other locations. The program plotted the path of the vehicle in black if the Orbiter was in a right wing down roll orientation, or white if the left wing was down. This is critical for HYTHIRM planning, as the best view of the Orbiter underside (the region of interest for measurements) was highly dependent on the roll angle, and had several ramifications, including changing the optimal viewing location to the other side of the ground track - a possible shift of 60 to $100 \mathrm{NM}$. A roll reversal occurred where the color changes. This is another region of the trajectory that is preferably avoided to optimize the view of the observation.

In addition to the customized virtual environment used as the primary display of ViDI output, EntrySim3D also prepared text files in the Google Earth KML format (Figure 10). The display mimics the ViDI display with the roll angle direction marked with black and white lines, and the locations where the integer Mach numbers lie are denoted by the red and green spheres. In addition, the Mach number values are annotated to each sphere as a text label. The Google Earth files have been extremely useful with the ground based assets, as the entire Google Earth database is available for reference. Given the operational preference for the ground systems to base themselves at small airports, one especially useful application was the inclusion of a world-wide airport database.

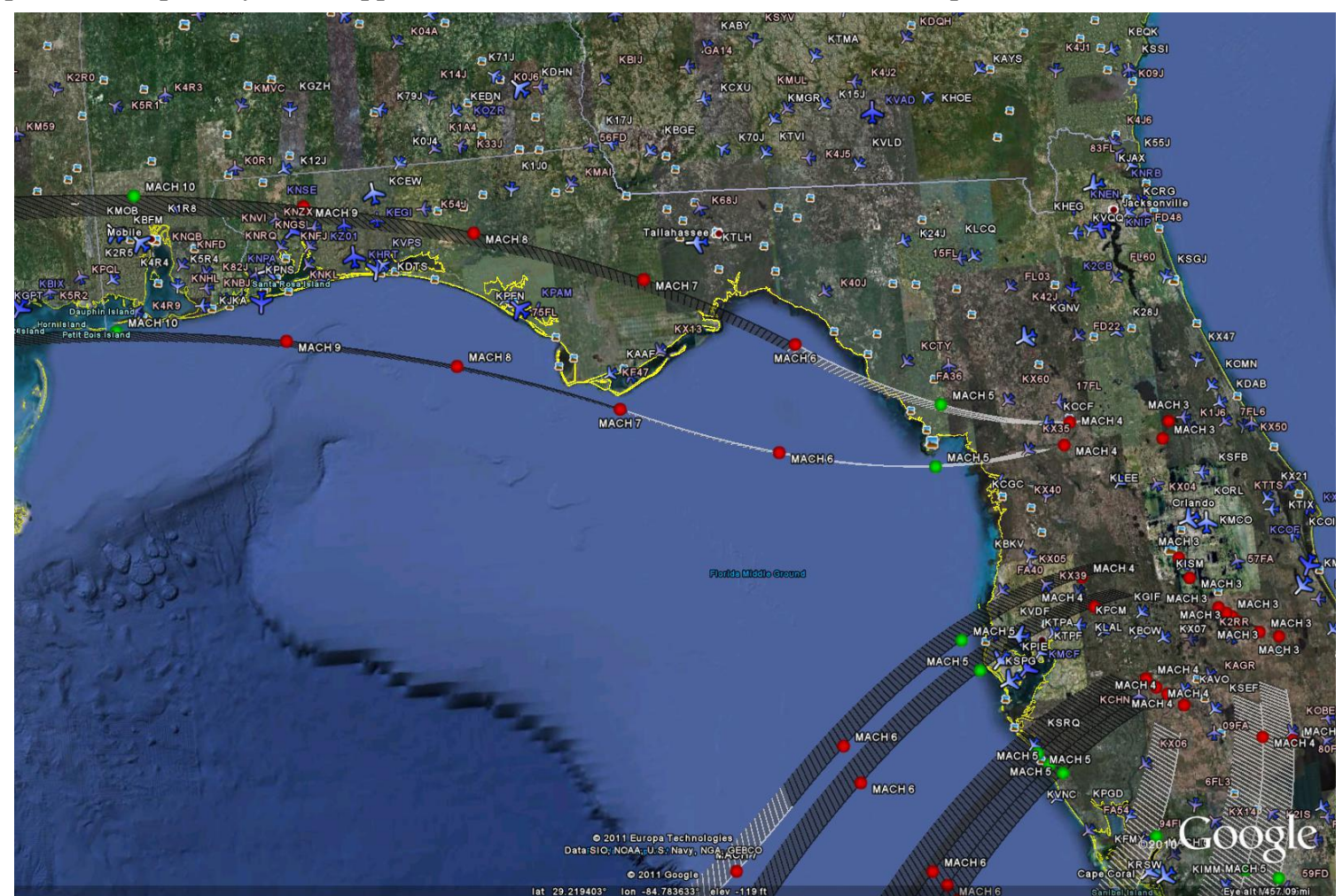

Figure 10. Google Earth display of potential STS-133 trajectories along with airport database. Each airport is depicted as a blue airplane. This capability greatly aids the planning of placement of ground based imaging assets. For this mission two MARS ground based units were targeted between Mach 5 and Mach 6 for the more southerly paths, or Mach 8 for the northern trajectories.

The EntrySim3D user also had the option of animating the Orbiter along the trajectory. A properly scaled model of the Orbiter was included in the global simulation and the location and orientation was set at each time step provided by the trajectory file. This created an animation file in which each trajectory input is a frame of the animation. To view the Orbiter, Entrysim3D had a camera creation and placement capability that located a virtual camera at a point either specified by a discreet latitude, longitude and altitude, or by a point on the Orbiter's trajectory and the range, bearing and altitude to that point (Figure 11). The virtual camera is then set to automatically track the Orbiter along the trajectory path. The camera field of view is set to match the specifications provided by the asset operators, and the rendering function of the visualization program can create high fidelity images with the same pixel resolution as the actual cameras used by the assets (Figure 12). This provided a simulated image, or a movie file, accurate down to the pixel level. Using this feature, multiple cameras could be set along the path at different viewing locations to determine the trade-offs between locations in concert with the orientation of the Orbiter. 


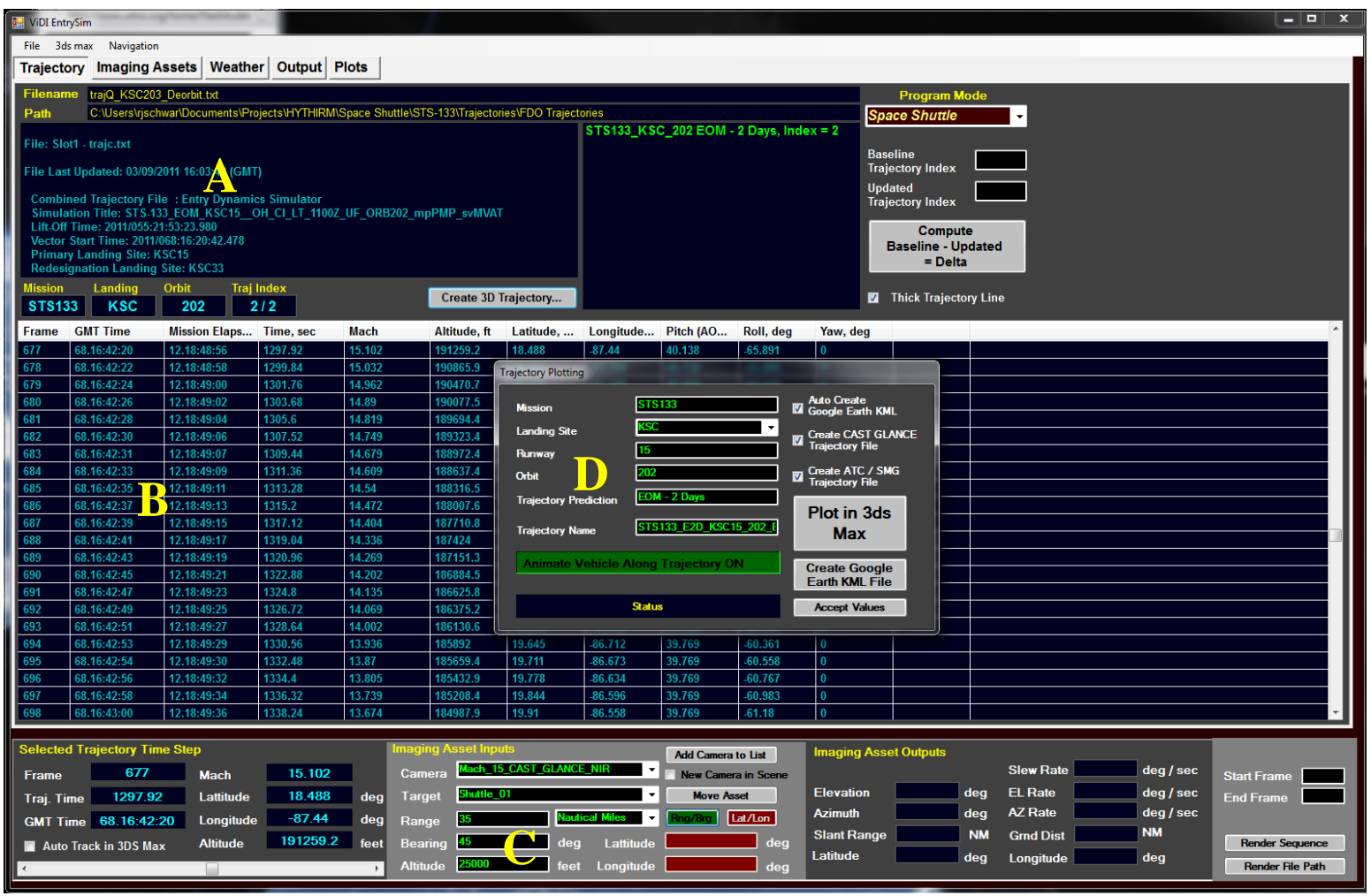

Figure 11. ViDI EntrySim3D user interface. The software is designed to minimize required user input to streamline data entry and prevent mistakes. Section A display trajectory file header, section B displays pertinent trajectory parameters. Section $C$ controls the placement of the virtual imaging camera, and screen D is the user control to plot a trajectory on a three-dimensional virtual globe.

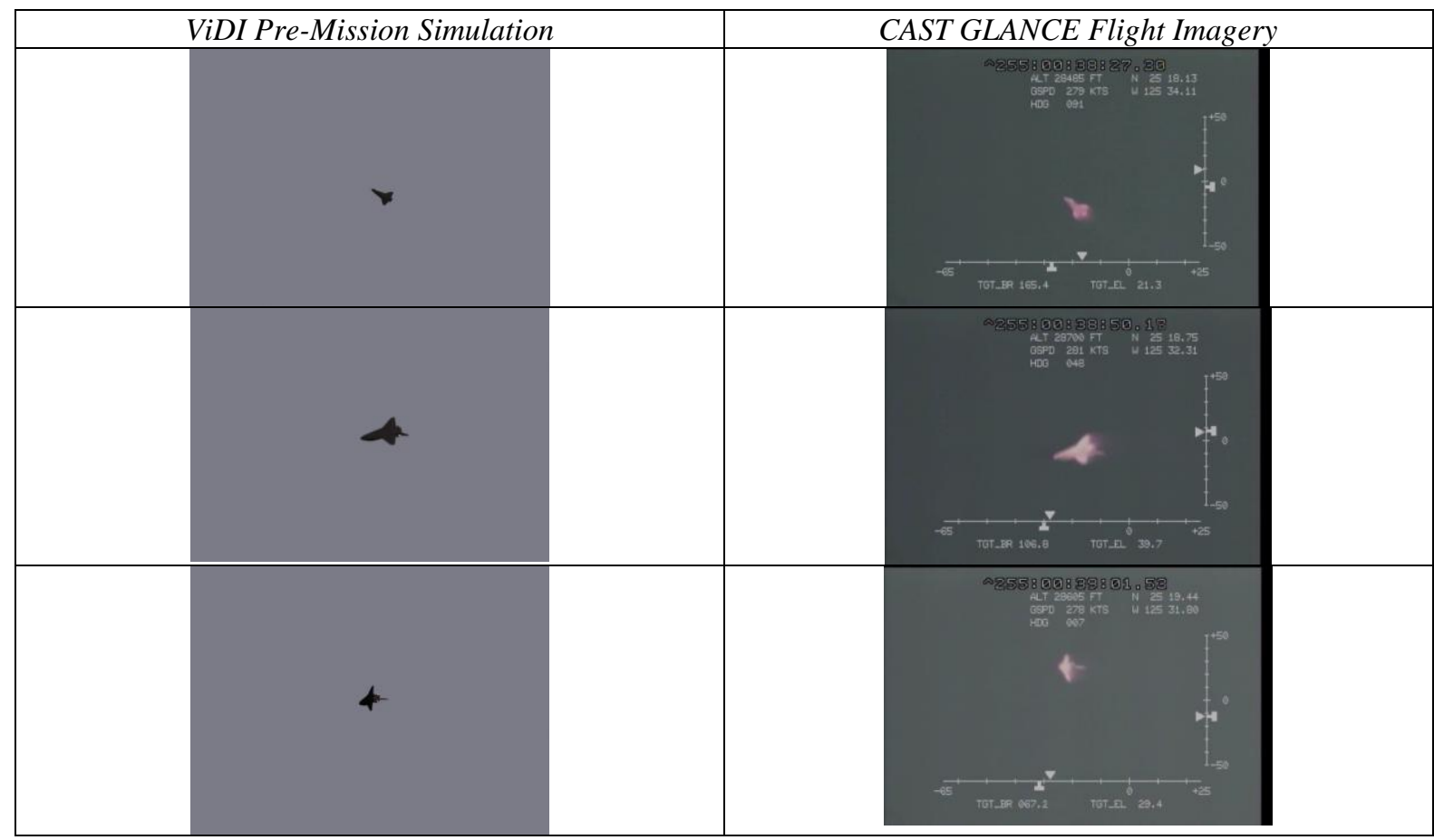

Figure 12. Frames from a ViDI pre-mission simulation animation on left compared to the CAST GLANCE in-flight video recorded in visible wavelengths on right for corresponding Mach numbers along the trajectory and planned CAST GLANCE position. Data taken from STS-128. 
Some additional features of EntrySim3D included determining the elevation and azimuth angles of the cameras, and the ability to compute the location and place a representation of the Sun in the virtual environment for any given time, date and location on the planet. The program can display the camera elevation and azimuth angles and the angle to the Sun as the camera tracks the Orbiter.

\section{E. Radiance Modeling}

As shown in Figure 1, early attempts at imaging the Orbiter were of limited engineering value due to image saturation. To maximize the image quality between signal to noise and minimize blurring there was a series of tradeoffs in camera settings. The exposure time, gain and aperture settings of the acquisition cameras have to be properly balanced to achieve the best results. Since the Orbiter observation occurred rapidly, there was little time to experiment with camera settings in real time. Thus, a radiance modeling effort was undertaken to provide baseline recommendations of what the optimum camera settings are expected to be. Starting with these settings the asset operator will then manually fine tune the settings as deemed necessary in real time.

To accelerate the capability of simulating actual detector response, an off the shelf code traditionally used by the Department of Defense to support an advanced scene generation capability was used to produce high-fidelity simulated infrared signatures of the Orbiter ${ }^{16}$. This radiance model was built around laminar and turbulent CFD surface temperature predictions of the Shuttle over a range of Mach numbers. The conversion to simulated sensor counts takes into account a number of observational, time, and/or environmental variables including: shuttle tile properties (emissivity and reflectivity, Shuttle location, temperature, and view-angle); Shuttle orientation; the Shuttle line of site viewing geometry; atmospheric radiative transfer models including the effects of sun and earthshine; and the sensor model.

In the waveband of interest, atmospheric radiance and transmittance is estimated with a widely used radiative transfer code MODTRAN25 [MODerate resolution atmospheric TRANsmission], a program designed to model the propagation of electromagnetic radiation through the atmosphere ${ }^{17}$.

The radiance model output is based in a visualization software environment that transforms three dimensional surface temperature input into surface radiant intensity and then projects the three dimensional intensity reaching the sensor onto a two dimensional plane that represents the detector array (Figure 13). The projection can be done for arbitrary orientations of the Orbiter. In terms of output, the radiance model also has the ability to graphically represent the optical systems expected resolution and image degradation (i.e., blurring) resulting from camera exposure time, atmospheric effects, optical bench motion and/or system optical diffraction limits via a point spread function, if known.
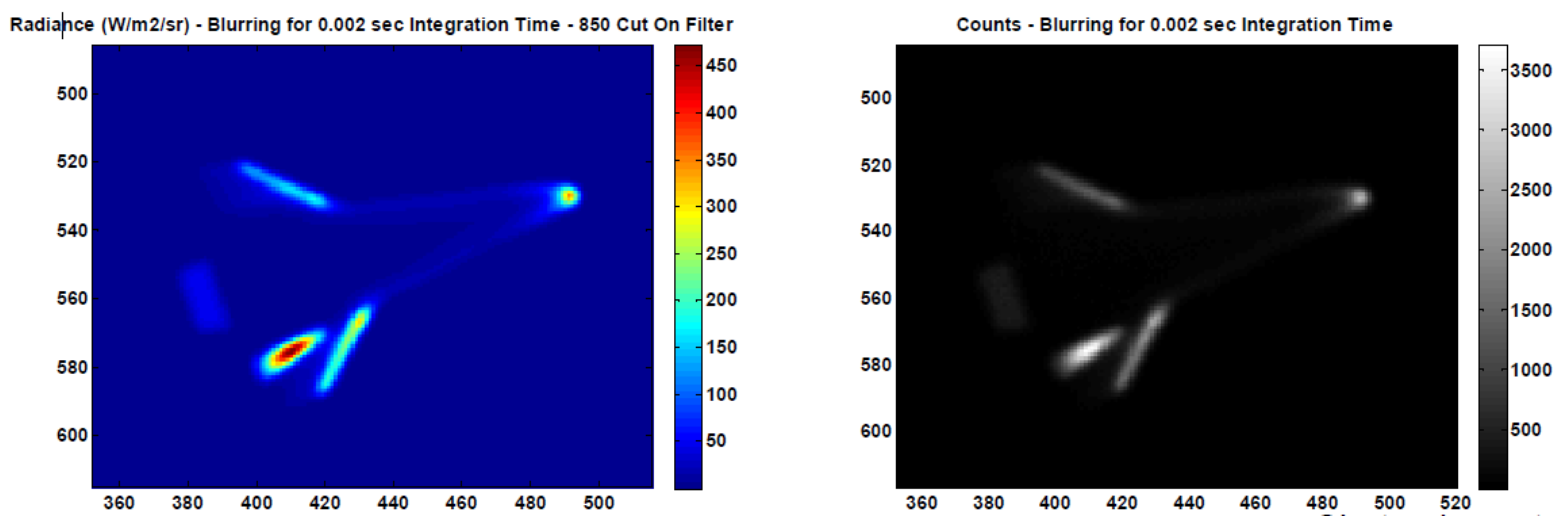

Figure 13. Radiance modeling output begins with computationally derived thermal distribution of the Orbiter for a given Mach number followed by modeling of the response of the infrared camera sensor and adding expected image blurring due to atmospheric effects.

\section{F. Ground Based Assets}

The HYTHIRM project utilized the Mobile Aerospace Reconnaissance System (MARS) from the Clay Observatory for ground based imaging. The MARS asset is a standalone telescope, tracking and data acquisition system that can be packaged into a van, plane or trailer for deployment (Figure 14).

The ground based asset team was made up of the asset owner, asset team technicians, and HYTHIRM support personnel. The asset owner led the technical operations for the ground based asset and served as the primary tracker during the reentry imaging. The asset technicians provided expertise in imaging sensors and operated the secondary cameras. The HYTHIRM support personnel served as the conduit for communication between HYTHIRM control 
and the ground based asset team. In addition to communications, the HYTHIRM support personnel led logistical operations and operated remaining imaging sensors. While deployed all team members worked together to set up and tear down all of the hardware systems. The MARS team members traveled with the imaging hardware to the deployment area where they were joined by HYTHIRM support personnel.

The asset owner was responsible for all ground transportation including transit to the initial deployment region. For STS-131 one of the two MARS assets were deployed via a NASA provided UC-12 aircraft. The asset owner transported the system to the aircraft and further positioning was then coordinated by the HYTHIRM project. The MARS assets arrived at the deployment region several days prior to landing prepared to collect data or redeploy based on changing conditions.

All communications during the mission from HYTHIRM control to the ground based assets were passed between the HYTHIRM Ground Asset Coordinator (GAC) and the HYTHIRM ground asset support personnel. The HYTHIRM support personnel collected and disseminated all information to the ground asset team and the GAC performed the same function at HYTHIRM control. The single link for communications simplified the spread of instructions and reduced the risk of misinterpreting information from multiple sources. While deployed the ground based asset team communicated with HYTHIRM control via cell phone and email. Regular updates of the ground asset team and daily summaries of key activities were relayed into HYTHIRM control through each day of deployment.

For STS-131 and STS-133 multiple MARS assets were deployed simultaneously to protect against landing opportunity wave-offs or data collects at multiple Mach number ranges. All deployment planning decisions were executed for, and communicated to, each asset, using the deployment processes described above, but scaled by the number of assets deployed.

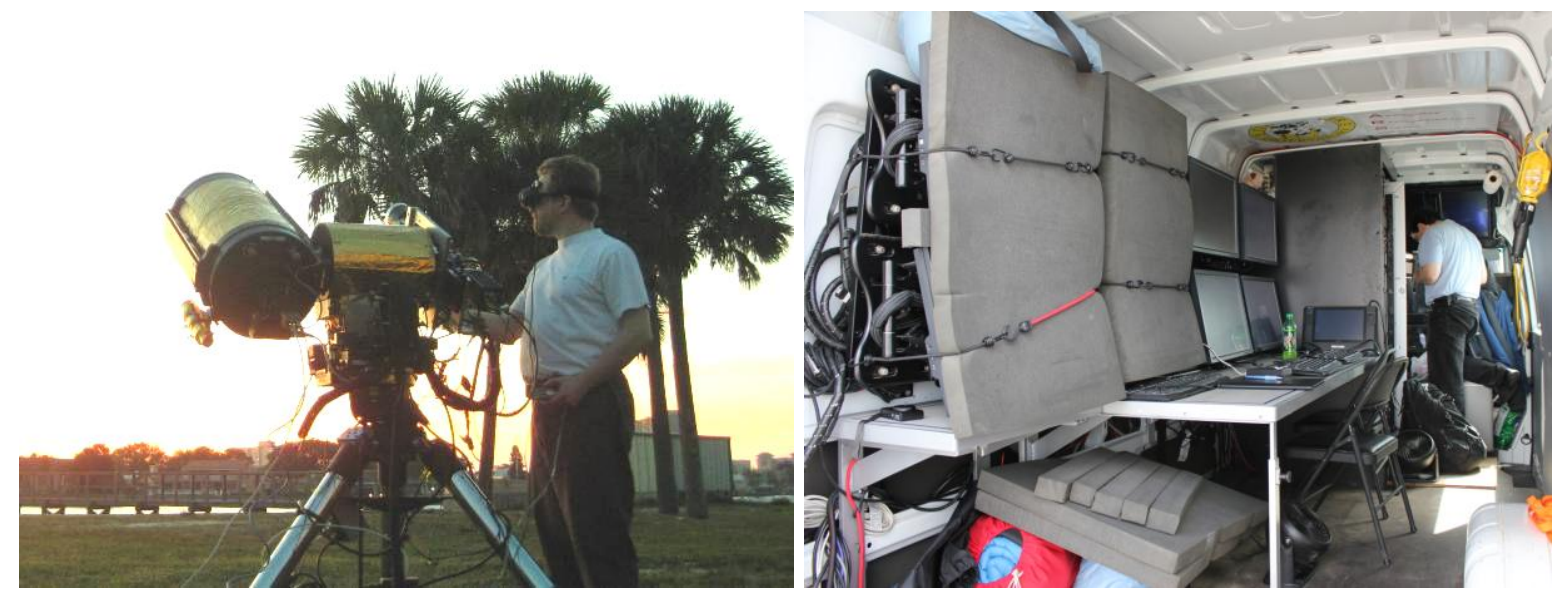

Figure 14. MARS Mobile telescope system. On left is the telescope and camera on mount. Note the operator's video display goggles, which provide a clear view of the video feed under all lighting conditions. On the right is the mobile support van with controlling and processing computers. Images are from the STS-133 deployment.

\section{G. Airborne Asset Flight Planning}

Numerous airborne imaging assets were considered for the HYTHIRM mission, but only the "Cast Glance" NP-3D aircraft from VX-30 at the Naval Air Warfare Center (NAWC) Pt. Mugu, CA, was used ${ }^{18}$ (Figure 15). This aircraft had the endurance and the equipment for long-range navigation and communications necessary for the non-CONUS operations required by HYTHIRM, as well as the unique imaging assets described elsewhere in this paper. The flight and imaging crews were also highly skilled in accomplishing the unique operational tasks associated with imaging high speed objects through narrow FOV (Field Of View) optics.

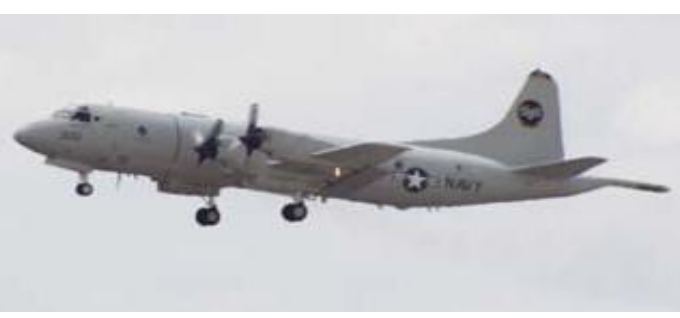

Figure 15. US Navy NP-3D CAST

\section{GLANCE aircraft operated by VX-30.}

The goal of HYTHIRM planning was to get this unique asset to the right place on the globe at the right time and with the right imaging conditions to collect thermal imaging data on the lower surface of the Shuttle at a predetermined target Mach number. This task involved both long-range planning activities and dynamic day-ofmission activities, and is done by the HYTHIRM AAC (Airborne Asset Coordinator) in cooperation with VX-30 
squadron representatives. The long-range activities primarily consisted of obtaining diplomatic clearances with the Central American countries from Panama to Mexico, over which trajectories on Space Station return missions passed. In the early HYTHIRM missions where lower Mach numbers were targeted, most imaging occurred in international airspace over the Gulf of Mexico. However, as the target Mach numbers increased the imaging aircraft needed to be positioned in or pass through the sovereign airspace of the Central American countries of Panama, Nicaragua, Guatemala, El Salvador, Costa Rica, Belize, Honduras, and Mexico. Roughly 90 days of lead time was needed to obtain the proper clearances. The high Mach data obtained by HYTHIRM would not have been possible without the cooperation of our Central American colleagues, and NASA is grateful for their assistance.

Once the diplomatic clearances were in place the next planning issue was aircraft basing. For the far southern trajectories over Panama basing from the Cooperative Security Location in El Salvador was desirable. However, the one-orbit waveoff trajectories that were generally over Mexico argued for basing from a Contiguous United States (CONUS) location, such as Corpus Christi NAS. Gulf imaging points argued for basing at Patrick AFB or Key West NAS. Missions that terminated in Shuttle landings at Edwards AFB could best be handled from Pt. Mugu. As of STS-133 only Pt. Mugu, Patrick AFB, and Corpus Christi were actually used. However, all necessary arrangements were made for the use of the other locations had final trajectory data shown these locations to be advantageous.

In addition to prior coordination of foreign airspace, the ground paths of some trajectories required U.S. airspace coordination. In particular, if the Shuttle entered on a "descending node" trajectory (Figure 6) that followed a curvilinear northwest to southeast path across the U.S., the imaging aircraft could be positioned in virtually any location, including airspace around high density airports. Early consultation with Federal Aviation Administration (FAA) Air Route Traffic Control Centers, if such a trajectory was expected, allowed proper planning to be in place to support all landing alternatives. Even on ascending trajectories penetration of the Special Use airspace along the southern U.S. and Gulf of Mexico was occasionally needed. To support these planning operations, a commercially available flight planning software package was employed (Figure 16).

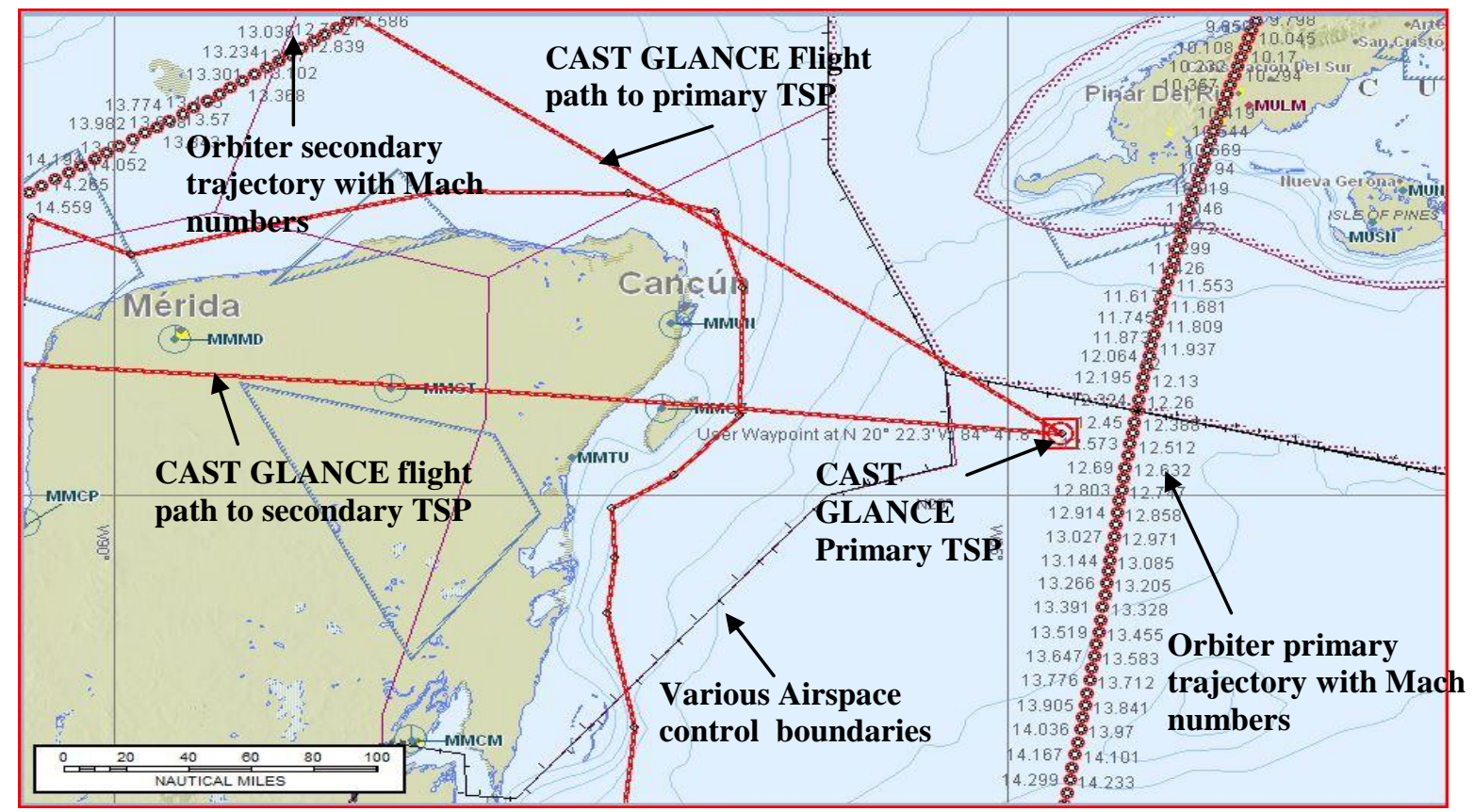

Figure 16. Detail of commercial flight planning software screen used in MCC for airspace coordination. The HYTHIRM Airborne Asset Coordinator will work with the flight crew and the HYTHIRM FAA representative located at SENEAM in Merida Mexico to clear airspace for observations and rapid repositioning from the primary observation to the secondary one-orbit wave-off observation point if required. Note Cuba in upper right, and the need to remain clear of Cuban airspace.

During mission execution it was necessary to communicate detailed positioning and timing information to the imaging aircraft as reentry parameters were refined. The HYTHIRM team accomplished this task by maintaining communications with the imaging aircraft via the Global HF network and Iridium-based satcom capability. It was also possible to relay messages to the aircraft through Central American Air Traffic Control (ATC) facilities if 
necessary. In order to facilitate coordination of air traffic clearances and communications HYTHIRM stationed an experienced FAA controller with appropriate language skills in Mexican ATC facilities during mission execution (See Dress Rehearsal / Operations in Foreign Airspace below). This assistance from the FAA and Mexico was crucial to the successful accomplishment of the later missions that were conducted almost exclusively in foreign airspace.

\section{H. Channels of Communications with the Imaging Assets}

Clear and timely communications between the Mission Operations personnel at MCC and the imaging asset operators were an important element of each HYTHIRM mission. These channels of communication were facilitated through the MCC landing Support Officers (LSO), and were tailored to meet the unique requirements of both the airborne and the land based imaging teams.

\section{Ground Asset Communications}

The primary communication link with the ground assets is via a teleconference bridge that is patched into another communication loop in the MCC. The ground assets dial into the teleconference via cell phone. Once all assets are present, this patch allows HYTHIRM Control to communicate directly with the ground assets from his communication panel.

\section{Airborne Asset Communications}

The primary communication link with the Cast Glance aircraft was via high frequency (HF) radio transmissions. An Iridium satellite telephone is available as a backup.

The prime HF station used was Cape Radio located at Cape Canaveral Air Force Station (CCAFS). Cape Radio also had remote access to the fifteen transmitters of the USAF High Frequency Global Communication System (HFGCS) to use as required. The HF link was routed from Cape Radio to the Detachment 3, 45th Operations Group Support Operations Center (SOC) located at Patrick Air Force Base, FL. Personnel in the SOC then patched the HF link to a common communication loop shared between the SOC and the MCC. Once all routing was completed, the final link allowed HYTHIRM Control in the MCC to key the HF transmitter from their communication panel in order to directly communicate with Cast Glance.

The location of CAST GLANCE was monitored using Google Earth. A position reporting tracking device provided by Air Force North (AFNORTH) fed updates into the Automated Flight Following (AFF) system managed by the U. S. Forest Service (USFS). These position reports are then shown in a Google Earth network link that was viewed on computers in the MCC.

\section{HYTHIRM Weather Forecasting}

The National Weather Service Spaceflight Meteorology Group ${ }^{19}$ (SMG) provided support to the HYTHIRM project from initial planning in 2008 to mission execution during Space Shuttle missions from 2009 through the present. Some unique aspects of the weather support were: the use of satellite cloud climatologies for pre-mission planning; the transfer of knowledge regarding flight control team deorbit burn decision-making due to weather impacts on Shuttle operations; and the exchange of weather and HYTHIRM mission planning information between SMG's weather display systems and the HYTHIRM projects planning tools.

SMG initially provided tailored cloud climatology data from both the International Satellite Cloud Climatology Project (ISCCP), and a surface station climatology to provide an outlook of expected cloud impacts on HYTHIRM operations throughout the Gulf of Mexico and Central America (Figure 17). The climatology data helped the HYTHIRM team evaluate the likelihood of success of using ground based systems versus airborne systems for the first mission. The cloud climatology data was also used in planning for subsequent missions to help the team evaluate the chance for success of imaging the Orbiter at locations associated with various desired Mach numbers. For example, the ability to image the Orbiter at high Mach numbers is generally more favorable for missions conducted during the winter than those in the summer due to the typical trajectory of the Orbiter for landing at Kennedy Space Center and the locations of semi-permanent weather systems along the coast of Central America.

The HYTHIRM team was able to refine and improve their concept of operations through mission simulations conducted with SMG and NASA flight controllers at JSC. The guidance SMG provided to the HYTHIRM team provided a better understanding of the Flight Director's landing decision-making process, particularly when weather was the key factor in the final de-orbit burn decision. These simulations were significant in allowing the HYTHIRM team to factor in the operational flexibility needed to adjust imaging asset locations when the Shuttle landing plan evolves rapidly during actual missions. This operational flexibility was demonstrated during STS-128 when the HYTHIRM team successfully decided 6-hours prior to landing to send the aircraft to the U.S. west coast in 
anticipation of the Flight Director's decision to forego a landing at Kennedy Space Center and de-orbit to Edwards Air Force Base.
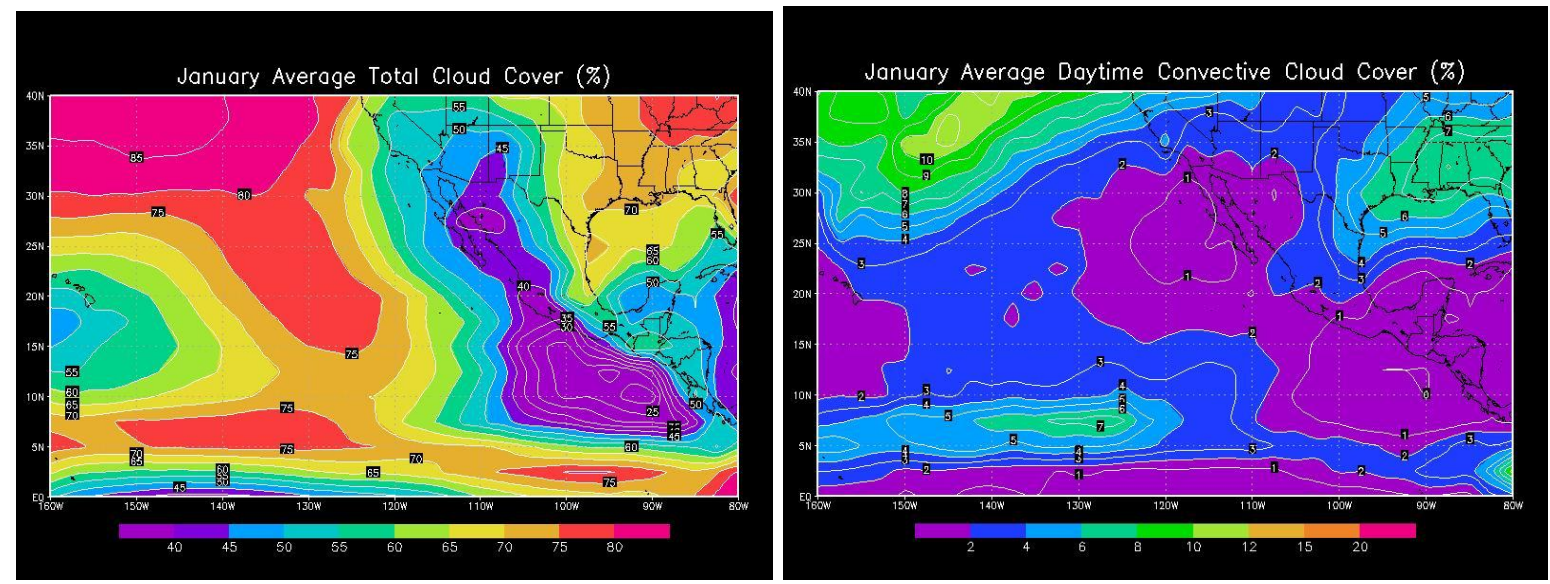

Figure 17. Total Monthly Average Cloud Cover is one of the datasets provided by SMG to provide background and expectations in the early pre-mission planning stages.

SMG supported real-time HYTHIRM operations during the Shuttle missions with both briefings and tailored products on a web site. Multiple face-to-face weather briefings occurred during the missions starting several days prior to the planned end-of-mission and culminating with a final weather briefing approximately 12-18 hours prior to landing. SMG customized the Advanced Weather Interactive Processing System (AWIPS) to superimpose Shuttle entry tracks onto satellite imagery and numerical model forecast data (Figure 18). These plan-views and cross-sections created highly effective visualization tools for the team. The HYTHIRM team also monitored the weather briefings from SMG for the mission Flight Director to make any final adjustments to the aircraft location. The weather products website for HYTHIRM, which facilitated self-briefings by HYTHIRM personnel between the scheduled face-to-face SMG briefings, provided information for mission planning including imagery and data that could be geo-located and integrated into HYTHIRM mission planning tools.
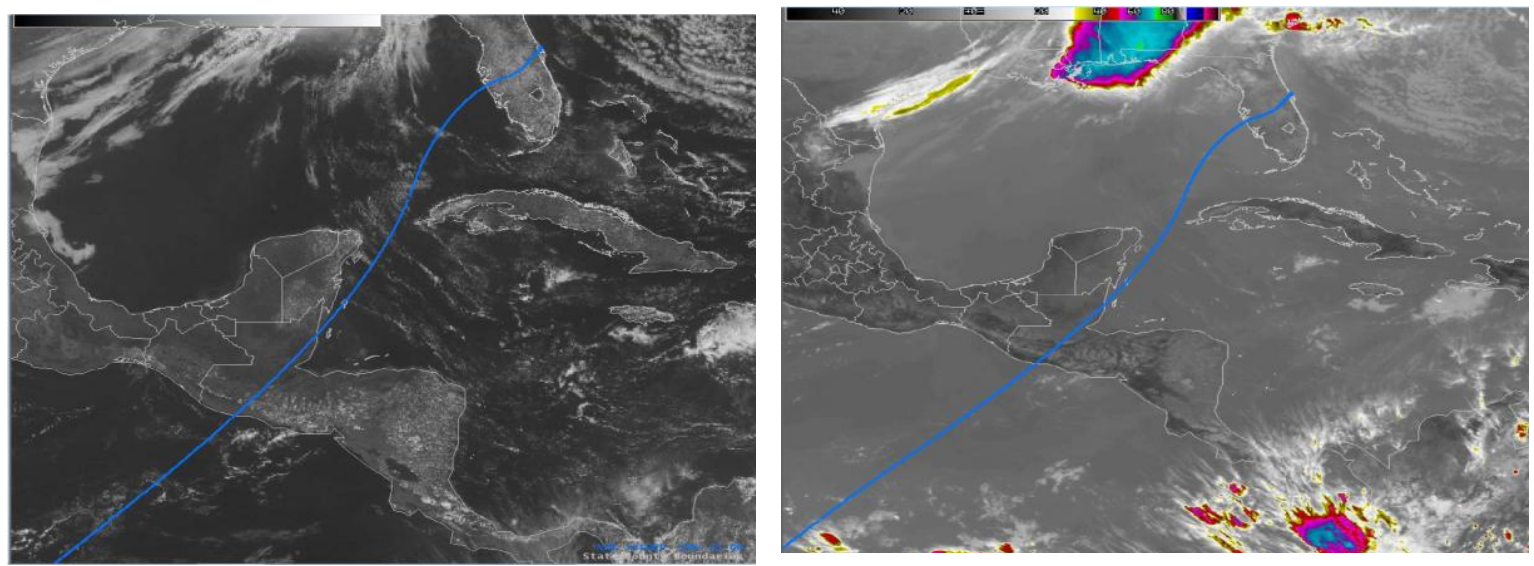

Figure 18. Visible satellite image on left and infrared satellite image on right produced by the AWIPS system with STS-133 trajectory overlay. SMG provided complete current conditions and forecasts for all locations where HYTHIRM operations were being planned for.

\section{Executing the HYTHIRM Mission}

With the launch of the Space Shuttle, the HYTHIRM team moved from the preparatory portion of the mission to the execution stage. The goal of the mission planning team that traveled to JSC was to understand the state of the Orbiter and be aware of how any changes to the baseline mission might affect reentry and in turn require changes to the planned HYTHIRM operations. To support this, a representative of the HYTHIRM MPT team typically arrived at JSC a few days after launch. The full team was in place six to seven days prior to the planned landing date. On a daily basis the HYTHIRM team followed Space Shuttle mission meetings, communicated with the Entry FDO, LSO, and received a detailed weather briefing from SMG. 


\section{A. Transit Flight / Ground Asset Deployment}

For the airborne imaging assets, deployment to the HYTHIRM operational base typically occurred five to six days prior to the planned EOM. For the early HYTHIRM missions the aircraft was based out of Patrick Air Force Base in close proximity to KSC. However, for later missions, especially once the decision was made to obtain diplomatic clearances for operations over foreign airspace Corpus Christi Naval Air Station (NAS), in Corpus Christi Texas became the location of choice. This reduced the required flight hours, made diversions to EDW easier, and placed the aircraft at an airfield that had infrastructure to support P-3 maintenance needs.

The transit flight was the first opportunity during a mission for the MPT at JSC to exercise all of the planned forms of communications with the aircraft. As discussed above, the LSO is integral in supporting the HF communications. As a backup satellite phone connections were employed, and test phone calls were placed during the flight. Additionally the HYTHIRM team tracked the location of the aircraft on FlightAware, a commercial web site that displays civilian aircraft positions in real time (Figure 19). The P-3 filed a flight plan under the "NASA 500" call sign to qualify as a civilian flight. This worked well but was limited to flights within CONUS. To obtain global flight following capability the HYTHIRM team used a Blue Force Tracker (BFT). These are small devices that are placed in the aircraft and send position information via satellite to a central DOD server computer accessed via a website or a Google Earth application.

The ground asset deployment varied depending upon the mission requirements. For STS-131 the MARS crew used a NASA provided UC-12 aircraft to move one imaging team and their telescope, while a second team was deployed from a highly customized mobile control center in a large van. For STS-133 both MARS teams traveled by land.

Prior to deployment, the land asset received predicted trajectories for calculation and planning purposes. The MARS team used their custom simulation software along with the HYTHIRM ViDI EntrySim3D to evaluate several TSP locations. The ground assets arrived at the deployment locations four or five days prior to landing, assuming a TSP was known. If there was uncertainty with the TSP, the assets found a secure location with conditions similar to the anticipated TSP location. The ground asset teams used the available days before the dress rehearsal to run through equipment setup, checkout, and tear downs each day in anticipation of the need to rapidly relocate for a 24 hour waveoff. The imaging systems had to be focused, sighted and calibrated before scientific data could be collected. The predicted trajectory files were used to evaluate the Orbiter position in the sky, sun exclusion and any interference to the line of sight to the target. The positions of the Orbiter in the sky vs. time and Mach number were computed and posted for easy reference, in case automatic tracking was lost during reentry. Every time the hardware was assembled, the ground asset team exercised the tracking system by locking onto local air traffic or other moving targets. The tracking practice verified the operation of the different tracking modes available prior to data collect. Throughout their deployment, the HYTHRIM control team constantly updated the ground assets on any changing conditions, especially weather. Based on the updates from HYTHIRM control, the ground asset could redeploy to a new TSP early in the deployment timeline.

\section{B. Dress Rehearsal / Operations in Foreign Airspace}

After asset deployment, and between calibration activities, final mission planning and reporting, and mandated crew rest periods, a dress rehearsal activity was planned. For the aircraft this was a flight that served two purposes. First, the aircraft flew into foreign airspace (always Mexico to date) to exercise the processes of working in foreign airspace with the appropriate airspace controllers. Support was provided by the FAA in this through the placement of a Spanish-speaking air traffic controller with the Servicios a la Navegación en el Espacio Aéreo Mexicano, or SENEAM the Mexican governmental airspace controlling authority. This HYTHIRM representative ensured rapid 
and accurate processing of requested air traffic control clearances for all HYTHIRM operations over Mexico and Central America.

The second purpose of the dress rehearsal was to practice all forms of communications to all assets, air or land based, in a manner similar to what would be carried out during the actual mission. Each asset also simulated a data capture. For the aircraft, the camera operator worked in close concert with the pilot and aircrew to coordinate maneuvers in the precision racetrack pattern they flew to properly position themselves for the data acquisition. As in the transit flight, the HYTHIRM MPT followed, and communicated with, the assets as required from the same consoles to be used during the mission in MCC.

For the ground based assets, the dress rehearsal was treated like an actual reentry opportunity with all communications occurring in real time to simulate data collection conditions as closely as possible. The ground based system ran through a full hardware and software set up and a communications check with HYTHIRM control. Simulated tracking was carried out at an arbitrary but pre-determined time to ensure all team members were familiar with the procedures and timelines that would be encountered during the actual data collection.

\section{Evolution of the Reentry Trajectory}

The HYTHTIRM team avidly followed the work performed by the FDOs during a mission in order to stay informed and have contingency plans ready should changes occur to the reentry trajectories. Several potential changes to the entry plan could occur once a Shuttle mission launched and many of these changes were modeled in the trajectories published by the FDOs at EOM - 2 days. After the Orbiter docked with the ISS, the FDO team evaluated a range of deorbit opportunities for EOM through EOM+2 days (the "+ days" signifying extra days spent in orbit beyond the planned EOM), and determined if an orbit adjust maneuver (OA) would be performed. There are numerous reasons an OA might be performed, including: providing more deorbit opportunities to a particular site on a given day, and targeting a particular reentry crossrange. A change in mission duration would have a significant impact, and atmospheric density changes due to solar activity could affect crossranges by a few nautical miles. The OA plan was solidified prior to the FDO's first official predicted EOM entry trajectory delivery on EOM-2 days.

Changes to predicted entry trajectories due to small dispersions might not be modeled in EOM-2 day (or even EOM-1 day) trajectory deliveries. Also, if there was extra propellant at the end of a mission, the Propulsion Officer might have requested out-of-plane (OOP) "wasting" during the deorbit burn to make post-flight processing of the Orbital Maneuvering System (OMS) propellant tasks easier. This was accomplished by firing the OMS engines in a direction other than the direction of travel, and perpendicular to the radial direction. The OOP direction was usually selected to decrease reentry crossrange. However, on EOM-1, the Pointing Officer examined the deorbit burn attitude and might have requested the OOP be in the other direction to ensure good communication with the Orbiter during the burn. All of these factors, and more, ultimately meant that the HYTHIRM team might not receive the entry trajectory prediction, taking into account all of the actual operational considerations, until a few hours before the deorbit burn.

\section{Final Planning - EOM - 2 days}

For most Space Shuttle missions, the Orbiter undocked with the ISS two days prior to reentry (EOM - 2 days, read as EOM minus two days). The FDOs were required to publish high fidelity reentry trajectories prior to the Mission Management Team meeting on the morning of undocking. Therefore, these trajectories were likely to be published one day prior to undock. Final HYTHIRM planning commenced once these trajectories were downloaded from the FDO web site, processed in the ViDI toolsets, and distributed to the team.

Using these trajectories, the asset operators created the baseline TSP that specified the exact timing and operations for the data acquisition. Additionally, this information was forwarded to the group responsible for the radiance modeling. This provided guidance on setting the cameras up for each imaging asset, as described above. Once the trajectories were distributed to the team, they typically had about one day to complete this final planning effort before a team-wide telecon was held to review the TSPs from each asset, discuss the radiance modeling, and obtain approval to proceed from project management.

One day prior to landing was reserved for crew rest. Both the airborne and the ground asset teams could use the day to continue any calibrations that remained or troubleshoot any issues that may have manifested during deployment. If any changes to the mission goals occurred after EOM-2 days, then the ground asset used EOM-1 to re-evaluate and relocate to a new TSP location.

To add to the workload, the assets had to plan for a minimum of two landing attempts per day, given the one orbit waveoff possibility, and they had to give consideration to 24- and 48-hour delays that were based on either weather conditions, or issues with the Orbiter. The FDOs typically updated the reentry trajectory predictions on a daily basis, so the asset owners would adjust their baseline plans as events unfolded. And as noted in the history 
section below, it was common for HYTHIRM missions to experience multiple waveoffs and significant changes to the baseline reentry plans.

\section{E. Mission Execution}

On the day of reentry, the first HYTHIRM team members to report to console at the MCC were the Airborne Asset Coordinator and Trajectory and Simulations, typically about six hours before the planned data collect, (and typically in the middle of the night!) This was timed to precede the start of the aircraft pre-flight, and the release of a set of trajectories from the Entry FDO team. There was a persistent tension in attempting to get the latest trajectory predictions from the FDOs in order to process and forward to the aircraft before they lost Internet connectivity as they started to taxi to takeoff. Most of the time, the transfer was completed on time. Nominally, the changes in the trajectories were on the order of a few nautical miles and a few tenths of a second, but every attempt was made to provide the most up-to-date information to the assets.

The ground asset team arrived on station at the TSP six hours in advance of the data collect to set up and verify the system. Trajectory updates were sent to the ground assets as they became available without pressure, as there was ample time to forward the information for their use.

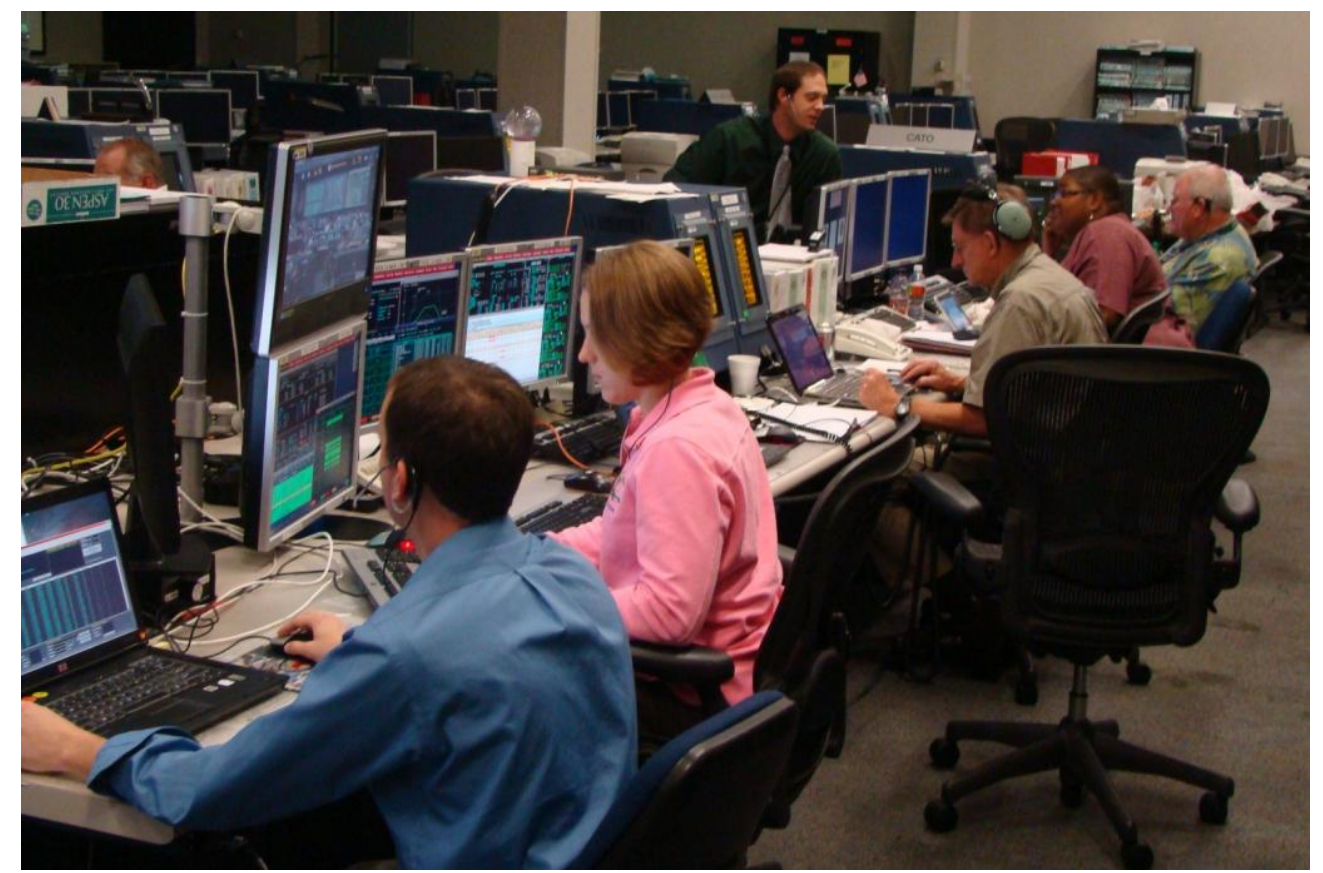

Figure 20. HYTHIRM Team in MCC Red Flight Control Room during operations. From left to right; ViDI EntrySim3D Operator, HYTHIRM FDO, Air Asset Communicator, VX-30 Squadron representative and CFLOS operator. MEPC is looking over the console from opposite side. Project management and the science team are sitting at the console one row ahead.

The airborne asset typically scheduled takeoff for three to four hours before the data collect, based on the staging location and the planned Mach number that was targeted for POC. During this time, the HYTHIRM team tracked the progress of the aircraft with the BFT, and communications checks were conducted via HF and satellite phone (Figure 20). The ground assets also conducted com checks and reported on their status. The majority of this time was spent following the progress of the mission controllers and flight crew, by listening in on key lines of audio communications, or "loops", as they prepared for reentry,. The MPT followed discussions from the Flight Director, SMG, and the FDOs, and a Space Shuttle FDO was present as part of the HYTHIRM team to answer detailed questions and interface as necessary with the mission controllers. The Space Shuttle Program followed a carefully choreographed routine of weather briefing, on-site observations at the landing fields, actions to prepare the vehicle and crew for reentry, and careful systems monitoring. The MPT endeavored to anticipate any possible actions on the part of the Flight Director in order to quickly respond to the situations as decisions became official. 
As the time of reentry approached, the Principle Investigator (PI) received constant updates from the CFLOS system (Figure 21). If the intended TSP position was predicted to have bad weather, updated information was relayed to the aircrew. On one mission this information was used to vector the aircraft to a small but suitable hole in the clouds. However, the landing was then delayed by 24 hours, due to inclement weather at KSC.

About ten minutes after the burn was completed, and about twenty minutes prior to the data collect, the FDOs published one last set of trajectory predictions. This information was immediately downloaded from the FDO web site, and processed in the ViDI visualization tools. It was typical to see changes on the order of $5 \mathrm{NM}$ to $10 \mathrm{NM}$ from the reference trajectory. These changes were then verbally transmitted to the aircraft as updated time, latitude and longitude positions for the Orbiter at the Mach number for the Point of Closest Approach (PCA). Additionally, the updated trajectories were emailed to the land based assets, with a verbal description of the changes. From this point on, the mission was primarily in the hands of the asset operators. A real-time display of the distance the orbiter was flying from the predicted trajectory was provided to

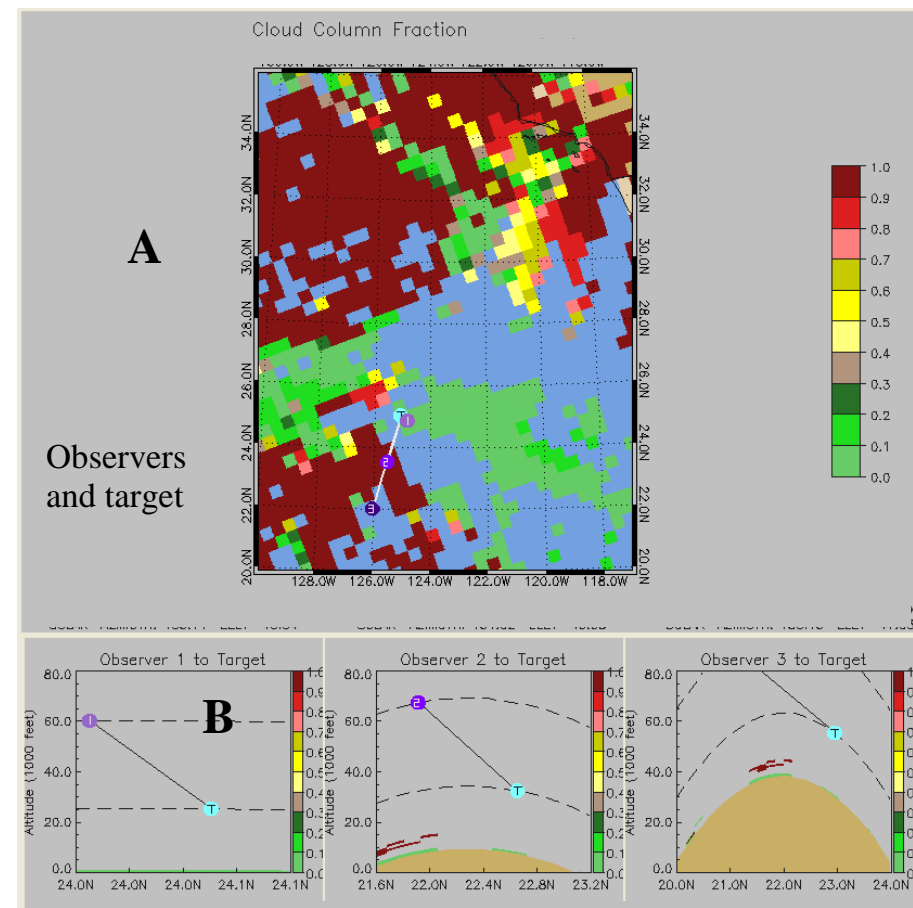

Figure 21. Cloud Free Line Of Sight (CFLOS) Software display shows the level of obstruction by clouds along the line of sight from the observer to the target. Section $A$ is a top view, while section $B$ is from the side, showing the relative altitudes of the target and cloud formations. This display covers three separate observers to the same target.

the team by the HYTHIRM FDO. This display reported how many nautical miles the vehicle was left or right of the predicted ground track. If the Shuttle was more than $5 \mathrm{NM}$ off of the prediction (which does occur, but rarely exceeds about $8 \mathrm{NM}$ ) a verbal report to the aircrew was provided to enhance situational awareness. Similar information was provided to the ground assets, and the ground assets also requested approximate Mach number callouts prior to and during the data acquisition.

The HYTHIRM team at MCC eagerly awaited reports from the assets following the data acquisition, and to date has not been disappointed. A typical data collect was from four to eight minutes. Once the Orbiter passed the assets, the HYTHIRM mission switched to closeout mode. In MCC, the HYTHIRM team stayed together and followed the aircraft as it returned to base and landed, and provided any information requested from the ground assets. A typical HYTHIRM shift was ten or twelve hours for the personnel in the MCC. The reward came a few hours later, typically as the team shared a meal and received the first images from the data collects via email.

\section{F. One Orbit and One-Day Waveoffs}

The weather at KSC sometimes posed challenges to landing the Space Shuttle. A strict set of weather criteria was applied to the Flight Director's decision to approve a landing. More often than not on HYTHIRM missions, at least one landing attempt, and sometimes many, were waved off due to bad weather. Delaying reentry by one orbit, or 90 minutes, moved the reentry trajectory several hundred miles north. As soon as a waveoff was official, the assets were notified. Every attempt was made to move the aircraft the required distance in the time allotted to prepare for a data collect. The aircrew had already pre-planned this move, and immediate airspace coordination between the foreign countries, as conducted by the FAA representative in SENEAM on behalf of the HYTHIRM project was crucial. To date, only two of the six HYTHIRM missions landed on the first attempt. There were also missions in which the Flight Director decided to waveoff both attempts into KSC for the day and wait to see if conditions improved at KSC the next day. A typical Shuttle mission had enough consumables to allow for two days of weather contingencies and one extra day in space to deal with mechanical anomalies. 


\section{G. Diversions to EDW}

The HYTHIRM team was tasked with observing the Orbiter at high Mach number on approach to KSC. However, on both STS-125 and STS-128 the Orbiter was ultimately diverted from KSC to EDW due to weather. Starting at more than a week before reentry, the daily weather briefings from SMG were critical in preparing the team for possible drastic changes in planning, as the longer-range forecasts kept predicting poor conditions for a landing at KSC. The challenge was to divert the P-3 aircraft from an observation point over the Gulf of Mexico, where it was initially planned to be, to a location hundreds of miles west of the coast of California, to make an equivalent observation for an landing at EDW. To do this, the aircraft would have to take off about six hours prior to the Orbiter's de-orbit burn. The dilemma was that the SSPO was determined to

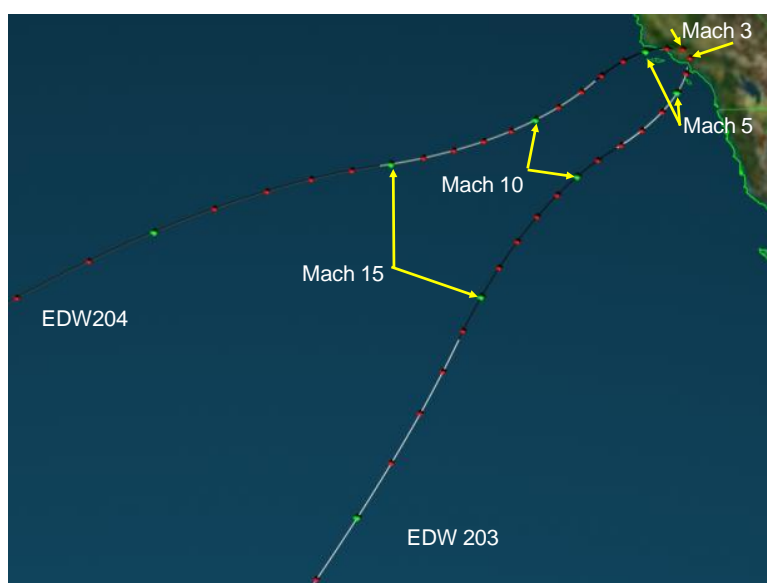

Figure 22. Typical ascending node reentry trajectory pair representing primary attempt (EDW203) and one orbit waveoff (EDW 204). make every effort to land at KSC to limit the time and cost of turning the vehicle around for the next mission. Thus, the Flight Director worked very closely with SMG, looking for a break in the weather at KSC, down to the last minutes prior to committing to a de-orbit burn. For both STS-125 and STS-128 the HYTHIRM team relied heavily on SMG, and on intuition, predicting that the weather would force a waveoff from KSC. With the aircraft well on its way to the Pacific Ocean the HYTHIRM team sat in excruciating anxiousness in MCC as the Flight Director and mission control team worked hard to find a way to land at KSC. On both occasion the weather did not permit a KSC landing, and data was successfully acquired over the Pacific Ocean in the minutes before the Orbiter landed at EDW.

\section{Summary of HYTHIRM Space Shuttle Missions}

Following the STS-124 and STS-126 flights, which were used for observation and training, the first HYTHIRM mission was conducted during the STS-119 mission, in March of 2009. HYTHIRM missions have continued through STS-134 in May of 2011, the final flight prior to submittal of this report. This covered seven Shuttle missions during that time period, including each of the five that carried the BLTFE experiment. Table 2 summarizes the Mission history. Below is a brief description of key events that occurred during each of the HYTHIRM deployments for observing the Space Shuttle.

Table 2. Summary of HYTHIRM Space Shuttle Missions

\begin{tabular}{|c|c|c|c|c|c|c|c|}
\hline Mission & Date & Orbiter & $\begin{array}{l}\text { BLT } \\
\text { FE }\end{array}$ & $\begin{array}{l}\text { Imaging } \\
\text { Assets }\end{array}$ & $\begin{array}{l}\text { Mach } \\
\text { Observations }\end{array}$ & Waveoffs & Comments \\
\hline STS-119 & $3-28-2009$ & OV-103 & Yes & $\begin{array}{l}\text { CG } \\
\text { MARS (1) }\end{array}$ & $\begin{array}{l}8.5 \\
\text { N/A }\end{array}$ & 1 orbit & $\begin{array}{l}\text { MARS in Florida had } \\
\text { bad weather }\end{array}$ \\
\hline STS-125 & 5-14-2009 & OV-104 & No & CG & 14.5 & $\begin{array}{l}21 \text {-day } \\
\text { delays, } \\
1 \text { orbit }\end{array}$ & $\begin{array}{l}\text { Landed EDW after two } \\
24 \text { hour waveoffs and a } 1 \\
\text { orbit waveoff to KSC }\end{array}$ \\
\hline STS-128 & $9-11-2009$ & OV-103 & Yes & CG & 15 & $\begin{array}{l}\text { 1-day } \\
\text { delay, } 1 \\
\text { orbit }\end{array}$ & $\begin{array}{l}\text { Landed EDW after one } \\
24 \text { hour delay and a } 1 \\
\text { orbit waveoff to KSC }\end{array}$ \\
\hline STS-131 & $4-20-2010$ & OV-103 & Yes & MARS (2) & 15 & $\begin{array}{l}\text { 1-day } \\
\text { delay, } 1 \\
\text { orbit }\end{array}$ & $\begin{array}{l}\text { Descending node, landed } \\
\text { KSC after } 24 \text { hour delay } \\
\text { and } 1 \text { orbit waveoff }\end{array}$ \\
\hline STS-132 & $5-26-2010$ & OV-104 & No & CG & 12.5 & None & \\
\hline STS-133 & $3-9-2011$ & OV-103 & Yes & $\begin{array}{l}\text { CG } \\
\text { MARS (2) }\end{array}$ & $\begin{array}{l}18 \\
\text { N/A }\end{array}$ & None & \\
\hline STS-134 & $5-15-2011$ & OV-105 & Yes & $\begin{array}{l}\text { CG (2) } \\
\text { MARS(1) }\end{array}$ & $\begin{array}{l}16.5 \\
6\end{array}$ & None & $\begin{array}{l}\text { Ground based system } \\
\text { obtained very high } \\
\text { resolution data }\end{array}$ \\
\hline
\end{tabular}


1. STS-119.

A one orbit waveoff was called about thirty minutes prior to the de-orbit burn. The CAST GLANCE aircraft crew was notified immediately, and set off to their secondary target location. They reached the secondary location with sufficient time to set up and acquire data successfully with the PCA at Mach 8.5. The data showed an unexpected asymmetrical boundary layer transition from a minor anomaly close to the nose landing gear door on the starboard side, an added bonus to the clearly seen fully developed turbulent wedge from the BLT DTO on the port side. A single MARS telescope was located on the west coast of Florida but was unable to obtain data due to the one orbit waveoff and bad weather.

1. STS- 125 .

Returning from the Hubble Space telescope, the Orbiter was delayed by two days due to bad weather in Florida. Then the first landing attempt to KSC was waved off and the subsequent opportunity to land at EDW was taken. Based on guidance from SMG, the HYTHIRM team gambled and sent the CAST GLANCE aircraft to an observation point over the Pacific Ocean in hopes of an EDW landing. This decision had to be made approximately six hour prior to an official decision by the Flight Director, and a landing at EDW was not assured. Data was collected at a PCA of Mach 14.5 prior to the Orbiter landing at EDW.

2. STS- 128

Once again bad weather delayed landing by a day, and poor conditions at KSC with a forecast of continuing poor conditions the next day led to a landing at EDW. Based on input from SMG and discussions with the Flight Director, a gamble was again made to position the aircraft over the Pacific Ocean to acquire data for an entry into EDW. As with STS-125, the decision to send the aircraft was made about six hour prior to the official decision by the Flight Director. CAST GLANCE flew around the edge of a hurricane to get into position and acquired data at a PCA of Mach 15.

3. STS-131

This was a rare descending node, bringing the vehicle down over CONUS. CAST GALANCE was not available for this mission, but two MARS telescopes were deployed. One was based in Minnesota to capture Mach 20, while the second unit was in Arkansas under the Mach 15 one-orbit wave-off path. The telescope positions were chosen due to weather considerations as well as science objectives. The crew in Minnesota was transported by a NASA UC-12 aircraft, while the Arkansas unit moved via a van. Due to weather considerations in Florida a one day delay and a one orbit delay were called, and observations of the Orbiter were made by the Arkansas MARS unit at a PCA of Mach 15.

4. $S T S-132$

The Orbiter reentered on the first opportunity. CAST GLANCE was positioned just south of restricted Cuban Airspace and made on observation at a PCA of Mach 12.5.

5. STS-133

The Orbiter reentered on the first opportunity. CAST GLANCE made an observation at a PCA of Mach 18 over Guatemala, while a MARS unit in St. Petersburg Florida acquired the vehicle at horizon break, but lost tracking due to clouds shortly thereafter. A second MARS unit was in the panhandle of Florida to cover a one-orbit waveoff should that have occurred.

6. STS-134

The Orbiter reentered on the first opportunity. Two CAST GLANCE imaging aircraft were dispatched to obtain data at Mach 18.5 and Mach 17.5. One aircraft had a malfunctioning optical tracking system and was unable to obtain data. The second aircraft moved down to the Mach 16.5 location due to bad weather, and acquired the Orbiter close to the PCA. NIR imagery was acquired of the aft portion of the Orbiter, and MWIR data was acquired of the wake. The MARS ground based system was located on the west coast of Florida. MARS tracked the Orbiter nearly from horizon to horizon and obtained excellent imagery in the Mach 6 to Mach 5 range.

\section{Lessons Learned}

One of the key elements of developing the HYTHIRM team and its mission operations had been the ability to first study, then practice and then implement. As part of the NESC assessment a HYTHIRM team member was able to observe Shuttle orbital and reentry operations from within the MCC for STS-124, two missions prior to STS- 119. Using insight gained on STS-124, several HYTHIRM team members then observed STS-126 with direct support of a Space Shuttle FDO, which evolved into the current "HYTHIRM FDO" team member position. Having had these experiences, these team members organized a mission simulation for the entire team at MCC, which relied heavily on the support and knowledge of the FDO. This exercise provided the knowledge and team building that led to the successful STS-119 data collect. This "crawl, walk, and then run" approach has allowed the team to approach 
enhanced procedures and increased capability in rational and productive ways as the HYTHIRM project has evolved.

This mentality was continued throughout all of the HYTHIRM operations. Following each mission a detailed lessons learned document was compiled with input from each team member. A team telecon was usually held a few weeks following the mission to discuss the lessons learned in detail. After every few missions a team meeting was planned that brought together all of the HYTHIRM personnel from all aspects of the project in person to review, critique, and diagnose past operations and broadly plan for future missions. This continuous process of analysis and improvement has allowed the HYTHIRM team to continually expand its operating envelope while maintaining mission success.

\section{Future Plans}

The mission operations for HYTHIRM will continue to evolve with missions for other spacecraft following the retirement of the Space Shuttle ${ }^{20}$. Some of the software toolsets will have to be made a bit more generic, considering they were heavily tailored to Shuttle operations, but the basic mission planning and operations infrastructure is sound. While the people, hardware and strategies employed by HYTHIRM have been successful in measuring the acreage surface temperature of the Shuttle lower surface during reentry, future hypersonic cruise vehicles or advanced launcher configurations will likely challenge affordable remote imaging capability in terms of requirements (i.e., high speed tracking, spatial/spectral resolution and temperature sensitivity). Future efforts of the HYTHIRM team will expand upon the emerging thermal imaging capability demonstrated to date and will explore the challenges and possibilities associated with developing and sustaining a next generation imaging system capable of supporting a much broader range of requirements and mission objectives. Better observational datasets are necessary for constraining model parameterizations and validation. A next generation imaging system would directly and indirectly support the development of critical enabling technologies including elements necessary for (but not limited to) hypersonic aerothermodynamics, high-temperature materials for thermal protection, flight dynamics, and range safety including launch and reentry.

\section{Summary}

The HYTHIRM project has successfully obtained spatially resolved, scientifically calibrated in-flight thermal imagery of the Space Shuttle during reentry (Figure 21). Starting with STS-119 in March of 2009 and continuing through the majority of final flights of the Space Shuttle, the HYTHIRM team has to date deployed during seven Shuttle missions with a mix of airborne and ground based imaging platforms. Each deployment of the HYTHIRM team has resulting in obtaining imagery suitable for processing and comparison with computational models and wind tunnel data at Mach numbers ranging from over 18 to under Mach 5. These missions lay the groundwork for the continuing collection of scientific data on hypersonic flight test vehicles, and the continued expansion of knowledge about hypersonic flight.
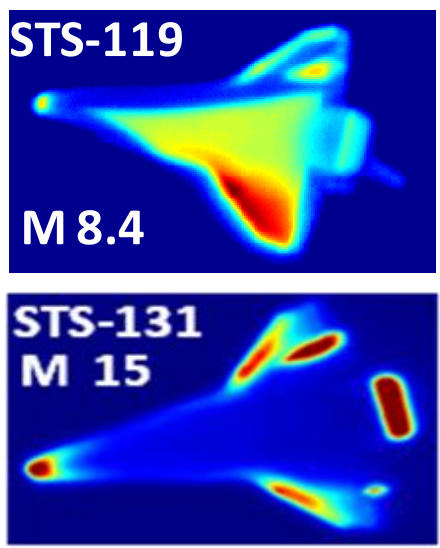
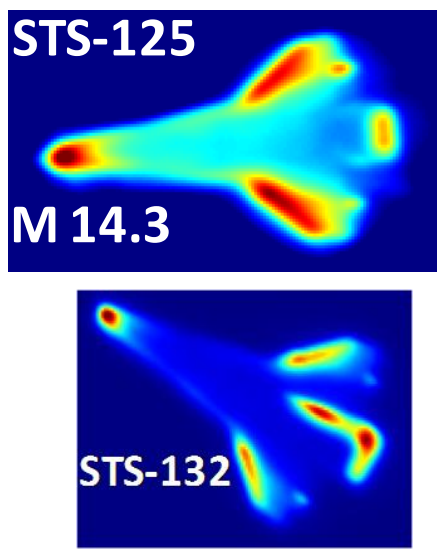
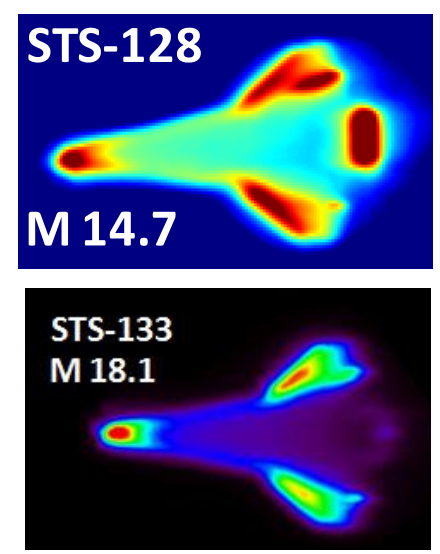

Figure 23. False color images of "unprocessed" infrared intensity data acquired on the HYTHIRM Space Shuttle missions (STS-134 false color images not processed at time of publication). Image processing and application of calibration data will transform these images into temperature distribution data with known uncertainties for direct comparison to computational predictions. 


\section{Conclusions}

The success of HYTHIRM was achieved through the application of careful mission planning, thorough training, and good communications at all phases of the project. The approach of initially observing and exploring the operational environment of the Space Shuttle Program at MCC and the subsequent training and simulation activities were of tremendous value in preparing for data collection missions. Subsequently, the toolsets available provided the flexibility and capability to meet the modeling requirements of the project. Also, the level of cooperation between the NASA centers, contractors and universities was extraordinary. Every individual involved with HYTHIRM was highly-motivated and provided value in many areas beyond their core responsibilities. The operational knowledge gained, and the scientific data collected from the HYTHIRM project has provided a solid core competency for enhancing the future of hypersonic flight testing.

\section{References}

1 Blanchard, R.C., Wilmoth, R.G., Glass, C.E., Merski, N.R., Berry, S.A., Bozung, T.J., Tietjen, A., Wendt, J., and Dawson, D., "Infrared Sensing Aeroheating Flight Experiment: STS-96 Flight Results," Journal of Spacecraft and Rockets, Vol. 38, No.4, 2001, pp.465-472.

2 Tietjen, A., Wendt, J., Dawson, D., Ahlgreen, R., Blanchard, R., Welch, S., Lovern, M., "ISAFE Infrared Sensing Aeroheating Flight Experiment" AIAA-BMDO Tech Conf paper 7-9, July 2000.

3 Berry, S.A., Merski, N.R., and Blanchard, R.C., "Wind Tunnel Measurements of Shuttle Orbiter Global Heating with Comparison to Flight," AIAA Paper 2002-4701, August, 2002.

4 Throckmorton, D.A., Zoby, E.V., and Kantsios, A.G., "Shuttle Infrared Leeside Temperature Sensing (SILTS) Experiment," AIAA Paper 85-0328, January, 1985.

5 Chocol J. C., "Infrared Imagery of Shuttle (IRIS)," Martin Marietta Corporation Final Report, MCR-76-564, Contract NAS29381, August, 1977.

6 “Infrared Imagery of Shuttle (IRIS) Experiment," IRIS/STS-3 Engineering Report, NASA-CR-193052, NASA AMES Research Center, June, 1982.

7 Green, M.J., Budnick, M.P., Yang, L., and Chiasson, M.P., "Supporting Flight Data Analysis for Space Shuttle Orbiter Experiments at NASA Ames Research Center," AIAA Paper 83-1532, June, 1983.

8 Schwartz, R., Ross, M., Baize, R., Horvath, T., Berry, S., Krasa, P., “A System Trade Study of Remote Infrared Imaging for Space Shuttle Re-entry," AIAA-2008-4023, June 2008.

9 Splinter, S., Daryabeigi, K., Horvath, T., Mercer, C.D., Ghanbari, C., Tietjen, A., Schwartz, R., "Solar Tower Experiments for Radiometric Calibration and Validation of Infrared Imaging Assets and Analysis Tools for Entry Aero-Heating Measurements," AIAA-2008-4025, June 2008.

10 Ross, M., Werner, M., Mazuk, S., Blanchard, R., Horvath, T. ., Berry, S. ., Wood, W., and Schwartz, R., "Infrared Imagery of the Space Shuttle at Hypersonic Entry Conditions," AIAA-2008-0636, 46th AIAA Aerospace Sciences Meeting and Exhibit, Reno, NV, Jan. 7-10, 2008

11Anderson, B.,Campbell,C.,Saucedo, L.Kinder,G.,Berger,K. "Boundary Layer Transition Flight Experiment Overview and In Situ Measurements", AIAA Paper 2010-240, January 2010

12 Berry, S., Horvath, T., Schwartz, R., Ross, M., Campbell, C., Anderson, B., "IR Imaging of Boundary Layer Transition Flight Experiments," AIAA-2008-4026, June 2008.

13 Gibson, D. M., Spisz, T. S., Taylor, J. C., Zalameda, J. N., Horvath, T. J., Tomek, D. M., Tietjen, A. B., Tack, S., and Bush, B.C., "HYTHIRM Radiance Modeling and Image Analyses in Support of STS-119, STS-125, and STS-128 Space Shuttle Hypersonic Re-entries," AIAA Paper 2010-244, Jan. 2010.

14 Wood, W. A., Kleb, W. L., Tang, C. Y., Palmer, G. E., Hyatt, A. J., Wise, A. J., McCloud, P. L., "Comparison of CFD Predictions with Shuttle Global Flight Thermal Imagery and Discrete Surface Measurements," AIAA Paper 2010-454, Jan. 2010.

15 Schwartz, R. J., McCrea, A. C., "Virtual Diagnostic Interface: Aerospace Experimentation In The Synthetic Environment," MODSIM World Conference and Expo., Oct., 14, 2009, Virginia Beach, VA

16 Crow, D., Coker, C., and Keen, W., "Fast Line-of-Sight Imagery for Target and Exhaust-Plume Signatures (FLITES) Scene Generation Program," Technologies for Synthetic Environments: Hardware-in-the-Loop Testing XI. Edited by Murrer, Robert Lee, Jr.. Proceedings of the SPIE, Volume 6208, June 2006.

17 A. Berk, L.S. Bernstein, D.C. Robertson, “MODTRAN: A moderate resolution model for LOWTRAN7”, Report GL-TR-890122, Air Force Geophys. Lab., Bedford, MA, 1989.

18 Tack, S., Tomek, D. M., Horvath, T. J., Verstynen, H. A., and Shea, E. J., "Cast Glance Near Infrared Imaging Observations of the Space Shuttle during Hypersonic Re-entry," AIAA Paper 2010-243, Jan. 2010.

19 Brody, Frank C., Richard A. Lafosse, Dan G. Bellue, Timothy D. Oram, 1997: Operations of the National Weather Service Spaceflight Meteorology Group. Wea. Forecasting, 12, 526-544.

20 Horvath, T. J., Tomek, D. M., Berger, K. T., Zalameda, J. N., Splinter, S. C., Krasa, P. W., "The HYTHIRM

Project: Flight Thermography of the Space Shuttle during Hypersonic Re-entry," AIAA Paper 2010-241, Jan. 2010. 